\title{
Revisiting the Role of Plant Transcription Factors in the Battle against Abiotic Stress
}

\author{
Sardar-Ali Khan, Meng-Zhan Li, Suo-Min Wang and Hong-Ju Yin * \\ State Key Laboratory of Grassland Agro-ecosystems, College of Pastoral Agriculture Science and Technology, \\ Lanzhou University, Lanzhou 730000, China; ali.khan13@lzu.edu.cn (S.-A.K.); limz11@lzu.edu.cn (M.-Z.L.); \\ smwang@lzu.edu.cn (S.-M.W.) \\ * Correspondence: Yinhj@lzu.edu.cn
}

Received: 23 April 2018; Accepted: 24 May 2018; Published: 31 May 2018

\begin{abstract}
Owing to diverse abiotic stresses and global climate deterioration, the agricultural production worldwide is suffering serious losses. Breeding stress-resilient crops with higher quality and yield against multiple environmental stresses via application of transgenic technologies is currently the most promising approach. Deciphering molecular principles and mining stress-associate genes that govern plant responses against abiotic stresses is one of the prerequisites to develop stress-resistant crop varieties. As molecular switches in controlling stress-responsive genes expression, transcription factors (TFs) play crucial roles in regulating various abiotic stress responses. Hence, functional analysis of TFs and their interaction partners during abiotic stresses is crucial to perceive their role in diverse signaling cascades that many researchers have continued to undertake. Here, we review current developments in understanding TFs, with particular emphasis on their functions in orchestrating plant abiotic stress responses. Further, we discuss novel molecular mechanisms of their action under abiotic stress conditions. This will provide valuable information for understanding regulatory mechanisms to engineer stress-tolerant crops.
\end{abstract}

Keywords: abiotic stress; gene expression; transcription factors; stress response

\section{Introduction}

The urgent demand for sustainable food production is still far from realization due to an alarming expansion of human population, along with uncertain threats linked with global climate deterioration, increasing soil salinization, and freshwater scarcity. Presently, approximately 800 million people are undernourished worldwide [1]. To feed the 9.6 billion people projected by 2050, an additional $70 \%$ increase in agricultural productivity is needed [2,3]. In nature, crop growth and productivity are adversely affected by various abiotic stresses, including extreme temperatures, salinity, drought, and other adverse conditions. Besides, crops suffering from abiotic stresses are generally more susceptible to biotic stress factors, such as pathogens, insects, and weeds, which increase the losses considerably. Together, these environmental constraints lead to more than $50 \%$ average yield losses for major crops globally [4,5]. Therefore, breeding stress-tolerant cultivars against multiple environmental stresses, with higher quality and yield, are required to match the food demands of the burgeoning human population [2]. Since the multigenic nature of abiotic stress traits and the narrow genetic pool have resulted in the limited success of traditional breeding, the use of transgenic technologies to breed stress-tolerant cultivars is currently becoming popular. Understanding the molecular principles and mining the stress-responsive genes that govern plant responses against abiotic stress factors is one of the prerequisites to develop stress-resistant crop varieties.

Being a sessile organism in nature, plants have evolved various intricate acclimatization strategies to combat unfavorable environmental conditions [6]. At the biochemical, physiological, 
and cellular levels, the production of phenylpropanoid-derived compounds and phytohormones, synthesis of antioxidants, cuticular wax, and osmolytes, adjustments of the membrane system, inhibition of cell growth and proliferation, and closure of stomata are associated with plant adaptive responses against abiotic stresses [7-11]. Similarly, at the molecular level, the stress-signaling pathways play key roles in plant abiotic stress response via linking the sensing mechanism and the genetic response. Generally, a stress signal transduction pathway comprises the following key steps: (1) signal perception; (2) signal transduction; and (3) stress response (Figure 1).

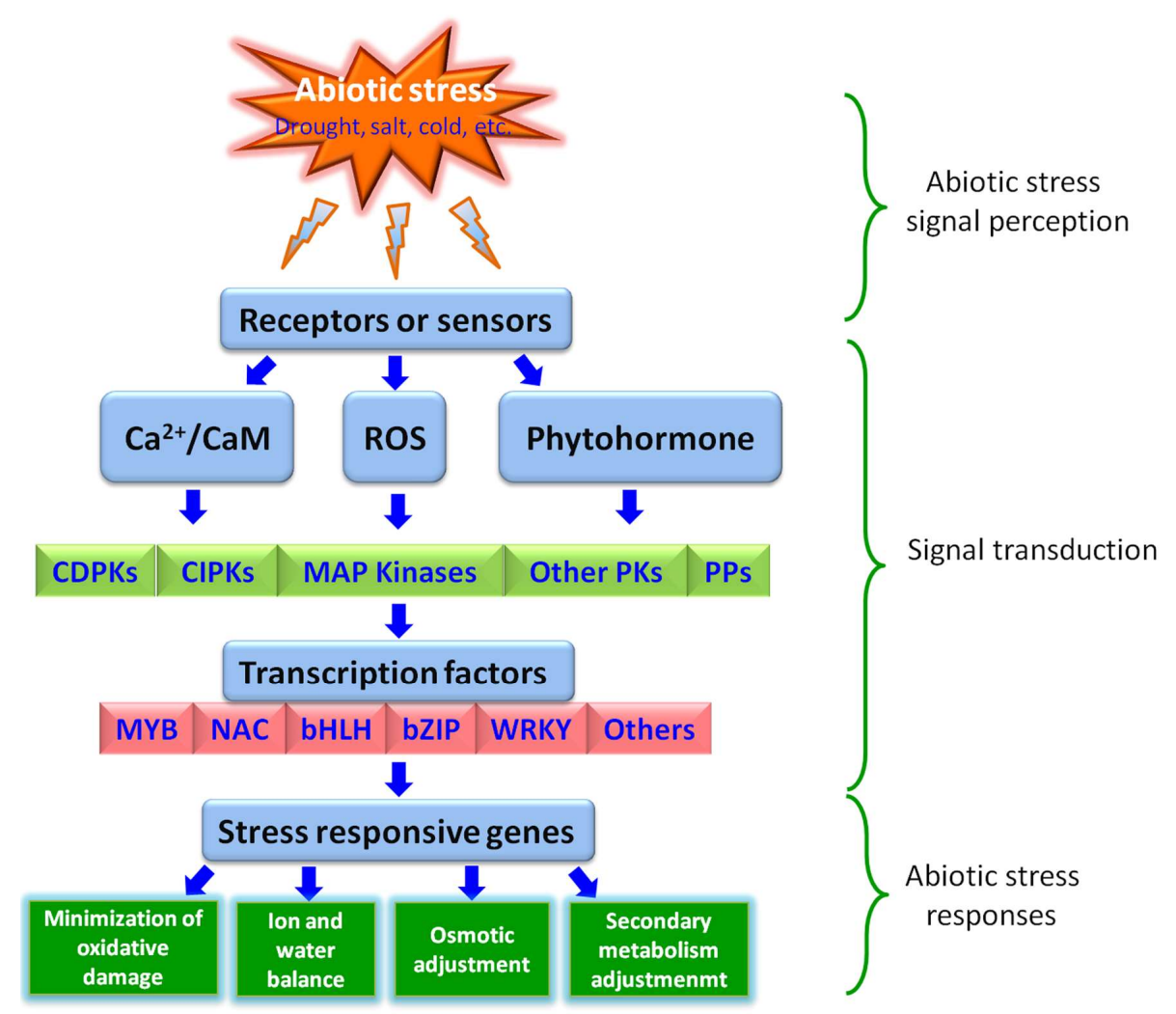

Figure 1. Model for transcription factors regulating abiotic stress-signaling pathways.

The first step in activation of a signaling cascade for any given abiotic stress is the recognition of stress signal via receptors located on the membrane of the plant cell. Recently, a body of researchers showed that various plasma membrane proteins, like COLD1 (CHILLING-TOLERANCE DIVERGENCE 1) [12], OSCA1 (reduced hyperosmolality-induced calcium increase1) [13], MSLs (MscS-like proteins) [14], CNGCs (cyclic nucleotide-gated channels), GLR (glutamate receptor-like) channels [15], histidine kinases, calcium channels (responsible for Ca fluxes), and GPCRs (G-protein-coupled receptors) [16] are the putative sensors for abiotic stress signals (Figure 1). After recognition, these sensors transmit the signal downstream through phytohormones and second messengers such as $\mathrm{Ca}^{2+}$ and ROS (reactive oxygen species) [17] (Figure 1). The second messengers, like ROS, trigger the activation of another set of ROS-modulated protein kinases (PKs) and protein phosphatases (PPs), including MAPK (mitogen-activated protein kinase) cascades, CDPKs (calcium-dependent protein kinases), CBLs (calcineurin-B-like proteins), CIPK (CBL-interacting protein kinase), and many other PKs, as well as PPs such as some PP2Cs (protein phosphatase 2Cs) (Figure 1). Subsequently, these PKs and PPs deliver the information downstream and trigger a series of phosphorylation/dephosphorylation cascades, especially the phosphorylation/dephosphorylation of transcription factors (TFs) $[18,19]$, that finally culminates either directly in the expression of functional genes involved in cellular protection, or indirectly in the expression of regulatory genes 
participating in signaling cascades and transcriptional regulation of gene expression $[20,21]$ (Figure 1). The expressions of all these stress-responsive genes mentioned above are regulated by TFs activated via phosphorylation/dephosphorylation. Contrary to functional genes, a single TF can regulate a cluster of downstream target genes. These abilities allow them to be excellent candidate genes for genetic manipulation of complex stress tolerance traits $[22,23]$.

To date, based on genome wide analysis, a great deal of TFs belonging to different families, such as MYB, bHLH, WRKY, bZIP, NAC, and so on, have been identified in different plant species [24-27]. Interestingly, functional analysis of a wide range of TFs via knockout/knockdown mutants and overexpression transgenic lines in model plants, as well as in different crops, have reported the involvement of TFs in the regulation of abiotic stress responses, such as in drought, salt, and cold tolerance (Table 1). In the present review, we specifically highlight the current developments in understanding TFs, with particular emphasis on their functions in orchestrating plant abiotic stress responses, and discuss novel molecular mechanisms of their action under abiotic stress conditions.

Table 1. Transcription factors involved in regulating plants in response to abiotic stresses.

\begin{tabular}{|c|c|c|c|c|c|}
\hline Gene Family & Gene & Identified in Crop & Studied Crop & Stress & References \\
\hline \multirow[t]{16}{*}{ MYB } & FtMYB9 & Fagopyrum tataricum & Arabidopsis & Drought/Salt & [24] \\
\hline & $1 R-M Y B$ & Cicer arietinum & Chickpea & Drought & [28] \\
\hline & MYB96 & Arabidopsis thaliana & Arabidopsis & Cold & [29] \\
\hline & GmMYB84 & Glycine $\max$ & Soybean & Drought & [30] \\
\hline & GmMYB12B2 & Glycine $\max$ & Arabidopsis & Salt & [31] \\
\hline & OsMYB55 & Oryza sativa & Maize & Drought & [32] \\
\hline & $O s M Y B c$ & Oryza sativa & Rice & Salt & [33] \\
\hline & MID1 & Oryza sativa & Rice & Drought & [34] \\
\hline & OsMYB91 & Oryza sativa & Rice & Salt & [35] \\
\hline & TaSIM & Triticum aestivum & Arabidopsis & Salt & [36] \\
\hline & $M t M Y B S 1$ & Medicago truncatula & Arabidopsis & Salinity & [37] \\
\hline & ARS1 & Solanum lycopersicum & Tomato & Salt & [38] \\
\hline & GaMYB62L & Gossypium arboreum & Arabidopsis & Drought & [39] \\
\hline & GaMYB85 & Gossypium arboreum & Arabidopsis & Drought & [40] \\
\hline & MdMYB88/MdMYB124 & Malus domestica & Arabidopsis/apple & Cold & [41] \\
\hline & PacMYBA & Prunus avium & Arabidopsis & Salt & {$[42]$} \\
\hline \multirow[t]{12}{*}{ bHLH } & AtbHLH68 & Arabidopsis thaliana & Arabidopsis & Drought & [43] \\
\hline & PebHLH35 & Populus euphratica & Arabidopsis & Drought & [44] \\
\hline & AtbHLH112 & Arabidopsis thaliana & Arabidopsis & Salt/Drought & [45] \\
\hline & OsbHLH068 & Oryza sativa & Arabidopsis & Salt & [46] \\
\hline & TabHLH39 & Triticum aestioum & Arabidopsis & Drought/Salt/Cold & [47] \\
\hline & FtbHLH2 & Fagopyrum tataricum & Arabidopsis & Cold & [48] \\
\hline & FtbHLH3 & Fagopyrum tataricum & Arabidopsis & Drought/Oxidative & [49] \\
\hline & AH & Solanum lycopersicum & Tomato & Low-temperature & [50] \\
\hline & PubHLH1 & Pyrus ussuriensis & Tobacco & Cold & [51] \\
\hline & ThbHLH1 & Tamarix hispida & Arabidopsis & Osmotic stress & [52] \\
\hline & TabHLH1 & Triticum aestivum & Tobacco & $\mathrm{Pi} / \mathrm{N}$-starvation & [53] \\
\hline & PtFIT & Populus tremula & Populus & Iron & [54] \\
\hline \multirow[t]{9}{*}{ WRKY } & OsWRKY47 & Oryza sativa & Rice & Drought & [55] \\
\hline & WRKY 71 & Arabidopsis thaliana & Arabidopsis & Salt & [56] \\
\hline & AtWRKY53 & Arabidopsis thaliana & Arabidopsis & Drought & [57] \\
\hline & ZmWRKY17 & Zea mays & Arabidopsis & Drought & [58] \\
\hline & OsWRKY71 & Oryza sativa & Rice & Cold & [59] \\
\hline & TaWRKY146 & Triticum aestivum & Arabidopsis & Drought & [60] \\
\hline & GmWRKY27 & Glycine max & Soybean & Drought/Salt & {$[61]$} \\
\hline & SlWRKY3 & Solanum lycopersicum & Tomato & Salt & {$[62]$} \\
\hline & MtWRKY76 & Medicago truncatula & Medicago & Salt/Drought & [63] \\
\hline
\end{tabular}


Table 1. Cont.

\begin{tabular}{|c|c|c|c|c|c|}
\hline Gene Family & Gene & Identified in Crop & Studied Crop & Stress & References \\
\hline & GhWRKY6-like & Gossypium hirsutum & Arabidopsis & Salt & [64] \\
\hline & RtWRKY1 & Reaumuria trigyna & Arabidopsis & Salt & [65] \\
\hline \multirow[t]{14}{*}{ bZIP } & AtABF3 & Arabidopsis thaliana & Alfalfa & Drought/Salt & [66] \\
\hline & OsABF1 & Oryza sativa & Rice & Drought & [67] \\
\hline & OsbZIP46 & Oryza sativa & Rice & Drought/Temperature & [68] \\
\hline & TaABL1 & Triticum aestivum & Arabidopsis & Cold/Drought/Salt & [69] \\
\hline & TabZIP6 & Triticum aestivum & Arabidopsis & Freezing & [70] \\
\hline & TabZIP60 & Triticum aestivum & Arabidopsis & Cold/Drought/Salt & [71] \\
\hline & ABP9 & Zea mays & Cotton & Salt/Drought & [72] \\
\hline & SlbZIP38 & Solanum lycopersicum & Tomato & Salt/Drought & [73] \\
\hline & EcbZIP60 & Eleusine coracana & Tobacco & Drought & [74] \\
\hline & GmbZIP110 & Glycine max & Arabidopsis & Salinity stress & [75] \\
\hline & GmFDL19 & Glycine max & Soybean & Salt/Drought & [76] \\
\hline & CaBZ1 & Capsicum annuum & Potato & Drought & [77] \\
\hline & GhABF2 & Gossypium hirsutum & Arabidopsis & Drought & [78] \\
\hline & BnbZIP2 & Boehmeria nivea & Arabidopsis & Drought/Salinity & [79] \\
\hline \multirow[t]{14}{*}{ NAC } & PbeNAC1 & Pyrus betulifolia & Tobacco & Cold/Drought & [80] \\
\hline & JUB1 & Arabidopsis thaliana & Arabidopsis & Dehydration & [81] \\
\hline & ANAC069 & Arabidopsis thaliana & Arabidopsis & Salt/Osmotic & [82] \\
\hline & GsNAC019 & Glycine soja & Arabidopsis & Alkaline & [83] \\
\hline & ONAC022 & Oryza sativa & Rice & Salt/Drought & [84] \\
\hline & TaRNAC1 & Triticum aestivum & Wheat & Drought & [85] \\
\hline & TaNAC47 & Triticum aestivum & Arabidopsis & Salt/Drought/Freezing & [86] \\
\hline & $M f N A C s a$ & Medicago falcata & Medicago & Drought & [87] \\
\hline & SINAC4 & Solanum lycopersicum & Tomato & Salt/Drought & [88] \\
\hline & SlNAC35 & Solanum lycopersicum & Tobacco & Salt/Drought & [89] \\
\hline & ZmNAC55 & Zea mays & Arabidopsis & Drought & [90] \\
\hline & $\mathrm{TaNAC} 2 L$ & Triticum aestioum & Arabidopsis & Heat & [91] \\
\hline & SINAM1 & Solanum lycopersicum & Tobacco & Cold & [92] \\
\hline & $N A C 26$ & Vitis amurensis & Arabidopsis & Drought & [93] \\
\hline
\end{tabular}

\section{Transcription Factors Involved in Abiotic Stress Responses}

\subsection{MYB Transcription Factors}

MYB (v-myb avian myeloblastosis viral oncogene homolog) proteins represent one of the largest TF families in plants, characterized by a highly conserved MYB domain (DNA-binding domain) at the N-terminus [94]. Based on the number of adjacent repeats in the MYB domain, MYB proteins are classified into four subfamilies, including R1-MYB, R2R3-MYB, 3R-MYB, and 4R-MYB, with 1, 2, 3, and 4 peptide repeats, respectively [95]. Among these subfamilies, R2R3-MYB is the largest subfamily, with 126 and 109 members in Arabidopsis and rice, respectively [25].

MYB TFs have been found to play a crucial role in the transcriptional control of numerous physiological and biochemical processes, including plant development, cell fate determination, and secondary metabolism [96]. In addition, MYB proteins are well documented for their involvement in mediating abiotic stress responses in many model plants and crop species $[28,97,98]$. For example, overexpression of Arabidopsis MYB96 TF in Camelina sativa promoted drought resistance, potentially through the accumulation of cuticular wax [99]. Recently, a study with Arabidopsis showed that this gene (MYB96) can be transiently induced by cold stress and ensures plant freezing tolerance via integration of cold and ABA (abscisic acid) signaling pathways [29]. Also, the expression level of AtMYB74 was dramatically increased under $\mathrm{NaCl}$ treatments and was shown to be transcriptionally regulated by the RdDM (RNA-directed DNA methylation) pathway via repressing the accumulation of 24-nt siRNAs under salt stress [100]. Likewise, knockdown of AtMYB14 by artificial microRNA increases cold stress tolerance via affecting CBF (C-repeat binding factor) genes, the knockdown approach strongly suggests an important role of AtMYB14 in low-temperature tolerance [101]. Besides, salt-related MYB1 (SRM1) negatively regulates seed germination and vegetative growth 
in Arabidopsis under salt stress [102]. In soybean, transcripts of GmMYB84 were induced by salt stress, drought, $\mathrm{ABA}$, and $\mathrm{H}_{2} \mathrm{O}_{2}$. Overexpression of $G m M Y B 84$ in soybean resulted in longer primary roots, high survival rates, and a lower dehydration rate under drought stress [30]. Additionally, GmMYB12B2 was drastically induced by $\mathrm{NaCl}$ treatment and UV irradiation, but not by drought, cold, and $\mathrm{ABA}$ stresses. Constitutive expression of GmMYB12B2 in Arabidopsis facilitated tolerance against UV radiation and salt treatment [31]. In rice, overexpression of a novel MYB-related protein, OsMYBR1, displayed greater tolerance to dehydration stress and reduced sensitivity to ABA in terms of higher soluble sugar and free proline levels [103]. Similarly, in maize (Zea mays), overexpression of OsMYB55 led to increased plant biomass and reduced leaf damage associated with exposure to high temperature and drought, possibly due to increased expression of stress-responsive genes [32]. In addition, a novel MYB protein, OsMYBc, was shown to regulate both the expression and role of OsHKT1;1 in controlling $\mathrm{Na}^{+}$concentration, which in turn prevents sodium toxicity in leaf blades of rice [33]. Using microarray data, Huang et al. [104] identified OsMYB511 from rice seedlings and revealed that this gene is an early regulator of cold stress response in rice, supported by dramatic induction of OsMYB511 under cold stress, and its high expression during the early developmental stage in panicles, interestingly accustomed to circadian rhythm regulation. Similarly, MID1 [34], OsMYB48-1 [105], and OsMYB91 [35] TF genes were reported to participate in salt and/or drought stress tolerance of rice. Moreover, a set of MYB TFs isolated from wheat (Triticum aestivum) has been shown to mediate abiotic stress responses. According to a more recent report, transgenic plants with overexpressed wheat TaSIM gene demonstrated significantly longer roots in addition to increased expression levels of genes (RD22, RD29A) linked to both ABA-dependent and ABA-independent signaling [36]. Likewise, transcription levels of TaMYB31 and TaMYB74 were upregulated in response to drought stress in wheat [106], while the increased dehydration tolerance in TaMYBsm1-D-harboring Arabidopsis lines was attributed to the high production of proline and poor malondialdehyde (MDA) content, as well as lower water loss rates [107]. Li et al. [24] found that FtMYB9 is rapidly induced in tartary buckwheat (Fagopyrum tataricum) on exposure to drought, salt, ABA, and cold treatments at the seedling stage. Elevated salt and drought resistances were obtained by introduction of FtMYB9 in Arabidopsis under the control of CaMV $35 S$ promoter, but, interestingly, the transgenic plants were highly sensitive to ABA at seed germination and seedling stages, accompanied by enhanced salt and drought tolerance. Nevertheless, the precise mechanism needs further investigation. Recently, Medicago truncatula MtMYBS1 TF was found to be able to boost drought and salt tolerance in Arabidopsis via a significant increase in primary root growth [37]. Likewise, two other MYB proteins, MtMYB3 and MtMYB61 from M. truncatula are involved in mediating cold tolerance [108]. Also, in tomato (Solanum lycopersicum), an MYB TF, SIAN2 positively regulates anthocyanin biosynthesis in vegetative tissues under high light and cold conditions [109]. Campos et al. [38] identified a salt-sensitive phenotype of tomato ars1 mutant, resulting from a single T-DNA insertion in the ARS1 gene, encoding an R1-MYB TF. Under salt acclimation, the mutant was able to accumulate high $\mathrm{Na}^{+}$in the leaves followed by a decrease in stomatal conductance and lower transpiration rate, indicating that the ARS1 gene contributes to stomatal movement under salt stress. In addition, ectopic expression of the cotton (Gossypium arboreum) GaMYB62L gene in Arabidopsis developed better drought resistance [39]. Similarly, GaMYB85 also promotes drought tolerance in transgenic Arabidopsis by elevating chlorophyll and free proline content, with a subsequent rise in relative water content [40]. Likewise, transgenic analysis of MdoMYB121 revealed that the enhanced tolerance against multiple abiotic stresses results from over accumulation of osmoprotectants in MdoMYB121-harboring apple (Malus pumila) and tomato plants [110]. Besides, a very recent study identified two R2R3 MYB proteins, MYB88 and MYB124 involved in promoting $\mathrm{H}_{2} \mathrm{O}_{2}$ detoxification and anthocyanin accumulation in apple under cold stress, suggesting their role in mediating cold tolerance [41]. Similarly, Fang et al. [111] also reported that the poplar (Populus tremula) PtrSSR1 gene, a member of R2R3 MYB family, is involved in elevating endogenous ABA content that leads to faster induction of lateral root emergence in transgenic Arabidopsis lines under salt stress, indicating that PtrSSR1 correlates with the regulation of LRE and ABA signaling to impart 
salt tolerance. In transgenic Arabidopsis, the decreased osmotic potential and elevated levels of peroxidase and proline content in response to salt stress were attributed to overexpression of the PacMYBA gene from sweet cherry (Prunus avium) [42]. Additionally, CiMYB5 and CiMYB3 cloned from chicory (Cichorium intybus) were shown to be involved in the degradation of the fructan pathway in response to abiotic stress [112]. Sun et al. [113] demonstrated that the Poncirus trifoliata PtsrMYB protein participates in dehydration tolerance, probably by modulation of polyamine synthesis due to regulation of the ADC (arginine decarboxylase) gene. Similarly, LpMYB1, cloned from Lablab purpureus, also mediates drought stress tolerance [114]. In addition, overexpression of ChiMYB, isolated from Chrysanthemum indicum, resulted in higher survival rates in Arabidopsis under salt stress [115]. Likewise, overexpression of the Jatropha curcas gene, JcMYB2, enhanced salt and cold tolerance of transgenic Arabidopsis [116]. Overexpression of MpMYBS3 in banana (Musa paradisiaca) conferred significantly higher cold tolerance [117]. On the contrary, transgenic tomato harboring the anthocyanin-associated R2R3-MYB TF, LeAN2, showed enhanced thermotolerance [118].

\section{2. bHLH (Basic Helix-Loop-Helix) Transcription Factors}

The bHLH (basic helix-loop-helix) transcription factors constitute the second largest family in angiosperms and are universally distributed in all eukaryotic organisms [43]. The highly conserved bHLH signature domain comprises two distinct functional regions, a basic N-terminal DNA-binding region, and a helix-loop-helix region involved in protein-protein interactions via the formation of homo- and heterodimeric complexes located at the C-terminal end, which is a prerequisite for TF function $[119,120]$. bHLH proteins form a monophyletic cluster and regulate gene expression in plants by recognizing and binding to the E-box (5'-CANNTG-30-3') and G-box (5'-CACGTG-3') consensus core DNA motifs present in the promoters of its target genes [121,122]. Since the first report of a bHLH TF gene in maize (regulatory gene $R$ ) [122], a considerable number of bHLH TFs have been reported in different plant species.

To date, functional analysis has revealed that bHLH transcription factors play critical roles in a myriad of biological processes, such as plant development [123], flavonoids biosynthesis [124], flowering [125], and photosynthesis [44]. Similarly, accumulating evidence has indicated that bHLH TFs also participate in regulating various abiotic stresses. For example, the expression of AtbHLH68, a putative non-DNA-binding bHLH gene, was altered in Arabidopsis in an organ-specific manner with exogenous application of $\mathrm{ABA}$, and its overexpression conferred transgenic plants significant drought resistance, likely via regulation of ABA homeostasis [43]. Further, AtbHLH112 overexpressors displayed better ROS-scavenging abilities, as well as elevated levels of proline that led to high resistance against multiple abiotic stresses, including salt and drought [45]. In another study, transcripts of bHLH122 were shown to be strongly induced by osmotic, drought and salt stresses, but not by ABA. In contrast to the bhlh122 loss-of-function mutant, $b$ HLH122 overexpressing lines were more resistant to osmotic, drought, and salt stress. Interestingly, $b H L H 122$ can significantly enhance cellular ABA levels via directly repressing the expression of $C Y P 707 A 3$, a key ABA 8'-hydroxylase required for ABA catabolism. The data suggest that $b H L H 122$ is positively involved in regulating abiotic stress tolerance in addition to repression of ABA catabolism [21]. Moreover, Babitha et al. [121] reported that co-overexpression of AtbHLH17 with AtWRKY28 in Arabidopsis, promotes abiotic stress tolerance in terms of longer roots and superior plant growth in response to mannitol and desiccation stresses, respectively. In Arabidopsis, higher accumulation of flavonoids due to overexpression of AmDEL, a bHLH TF, was reported to be a positive response against salt and drought stress [126]. Functional characterization of OsbHLH068 and its homologous gene, AtbHLH112, revealed that, while both these genes have opposite roles in controlling flowering phenotypes, they share partially redundant functions to confer salt stress tolerance, as shown by prolonged root length and lower accumulation of $\mathrm{H}_{2} \mathrm{O}_{2}$ under salt stress [45]. In wheat, gene expression analysis showed that TabHLH39 is induced in response to salt, polyethylene glycol, and cold, and exhibits differential expression patterns in roots, stems, and leaves. Transgenic Arabidopsis with overexpressed TabHLH39 displayed significant resistance to multiple 
abiotic stress conditions during the seedling stage via altered physiological indices [47]. Very recently, FtbHLH2, cloned from Tartary buckwheat was reported to elevate cold tolerance, as observed with higher photosynthetic efficiency and lower reactive oxygen species (ROS) in transgenic plants under cold stress [48]. Likewise, the improved drought/oxidative stress resistance of FtbHLH3-overexpressing Arabidopsis lines was attributed to lower MDA and higher activation of the antioxidant system than the wild type (WT) [49]. In addition, the tomato Hoffman's anthocyaninless gene, $A H$, encoding a bHLH TF, is involved in enhancing low-temperature tolerance in tomato seedlings via accumulating a greater amount of anthocyanin and regulating abiotic stimuli genes [50]. Similarly, ectopic expression of PebHLH35 from Populus euphratica provided tolerance against water-deficit stress through changes in several anatomical and physiological parameters, such as stomatal aperture, stomatal density, and photosynthetic and transpiration rates [44]. Similarly, the stress-induced PtrbHLH from P. trifoliate [127], MabHLH1/2/4 from banana [128], PubHLH1 from pear (Pyrus ussuriensis) [51], and ThbHLH1 from Tamarix hispida [52] have been shown to enhance tolerance against abiotic stresses. Additionally, some bHLH TFs involved in regulating element-deficiency and iron stress responses have been reported. For instance, TabHLH1 overexpressing plants displayed improved tolerance against $\mathrm{N}$ and Pi starvation via transcriptional regulation of nutrient transporter genes NtPT1 and NtNRT2.2 [53]. Besides, transgenic plants overexpressing Arabidopsis bHLH34 and bHLH104 demonstrated increased expression of iron (Fe) deficiency-responsive genes and $\mathrm{Fe}$ accumulation. By contrast, loss-of-function of bHLH34 and bHLH104 resulted in the reduction of Fe content and disruption of Fe deficiency response [129]. Similarly, using multiple knockout mutants, Wang et al. [130] reported that, in Arabidopsis, bHLH38, bHLH39, bHLH100, and bHLH101 play vital roles under limiting iron conditions and are required for activation of Fe deficiency responses and uptake. Moreover, functional analysis of the triple knockout mutant bhlh39 bhlh100 bhlh101 revealed that these TFs act in the iron intake and internal metabolic responses to Fe deficiency [131]. Also, CmbHLH1 from chrysanthemum (Chrysanthemum morifolium) regulates iron uptake via $\mathrm{H}^{+}$-ATPase-mediated acidification of the rhizosphere under Fe deficiency [132]. Likewise, in Populus tomentosa, PtFIT is involved in conferring Fe deficiency tolerance, as indicated by elevated chlorophyll content and Chl $\mathrm{a} / \mathrm{b}$ ratio in overexpressing transgenic plants [54].

\subsection{WRKY Transcription Factors}

WRKY proteins cover a large group of transcription factors that can be found throughout the green plants. The common feature of WRKY proteins is the presence of an approximately 60-amino-acid DNA-binding domain, known as the WRKY domain, followed by a zinc-finger motif at the C-terminus [133,134]. WRKY family proteins are categorized into three distinct groups (I, II, and III) according to the number of WRKY domains and zinc-finger motifs [135]. Most WRKY proteins were found to recognize and bind specifically to W-box (TTGACT/C), a consensus cis-element commonly found in the promoters of many defense and abiotic stress response-related genes, implying that they play important roles in plant biotic and abiotic stress tolerance [135,136].

Recent knowledge has shown that WRKY proteins participate in various abiotic stresses in different plant species [55,137]. For example, WRKY46, WRKY54, and WRKY70 were found to cooperate with BES1 TF in Arabidopsis to promote brassinosteroid (BR)-regulated plant growth, but negatively regulate dehydration tolerance [138]. Salinity-inducible WRKY71 has been shown to hasten flowering in Arabidopsis under salt stress, thereby helping the plant to complete its life cycle earlier in order to escape salt stress [56]. Sun et al. [57] observed that activated expression of AtWRKY53, a member of group III WRKY proteins, can modulate stomatal movement via boosting starch metabolism that facilitates stomatal opening, and by reducing $\mathrm{H}_{2} \mathrm{O}_{2}$ content in guard cells, thus negatively participating in regulating dehydration tolerance. Further, heterologous expression of maize ZmWRKY17 in Arabidopsis resulted in reduced ABA sensitivity—as indicated by healthy green cotyledons and longer roots-in response to exogenous ABA application nevertheless increased plant sensitivity to $\mathrm{NaCl}$ stress [58]. Similarly, in rice, OsWRKY30 and OsWRKY47 have been reported 
to participate in conferring drought stress tolerance. Meanwhile, OsWRKY71 functions as a positive regulator of cold tolerance by regulating the expression of downstream target genes, such as OsTGFR and WSI76 [55,59,139]. In a similar manner, a rice transcriptional repressor, WRKY76, not only mediates cold stress tolerance but also has a function in plant defense against blast disease through enhanced expression of abiotic stress-related genes and suppression of PR genes, respectively [136]. TaWRKY146 cloned from wheat exhibited significant expression in the leaves and roots of wheat seedlings following osmotic stress and rendered drought tolerance to transgenic Arabidopsis via facilitating stomatal closure [60]. Similarly, the enhanced drought and salt tolerance observed from TaWRKY10 transgenic tobacco was attributed to a reduction in ROS accumulation and regulation of osmotic balance [140]. Additionally, TaWRKY93 improved abiotic stress tolerance in overexpressing transgenic Arabidopsis, as indicated by longer primary roots and more proline content compared to WT [137]. In soybean, the genetic analysis demonstrated that GmWRKY27 enhances salt and drought tolerance, supported by measurements of proline and ROS content [61]. Besides, a recent study uncovered that overexpression of tomato SIWRKY3 protein promotes physiological indices associated with photosynthesis, higher accumulation of $\mathrm{K}^{+}$and $\mathrm{Ca}^{2+}$ in the leaves, and reduced sodium and proline content [62]. Likewise, SIWRKY39 and SIDRW1 conferred both biotic and abiotic stress tolerance to tomato via activating the expression of both stress and pathogenesis-related genes [141,142]. In transgenic M. truncatula, MtWRKY76 interacts with the ASR protein, as well as triggers the induction of abiotic stress-responsive genes, resulting in improved drought and salt tolerance [63]. Similarly, a GhWRKY6-like gene from cotton (Gossypium hirsutum) was found to be involved in scavenging reactive oxygen species and activating the ABA signaling pathway, thereby enhancing salt tolerance in Arabidopsis. By contrast, silencing of the GhWRKY6-like gene through VIGS (virus-induced gene silencing) in cotton increased abiotic stress sensitivity [64]. Equally, two other WRKY genes from cotton, GhWRKY41 and GhWRKY68, positively regulate salt and drought stress tolerance via affecting numerous physiological indices, such as stomatal closure and ROS accumulation in transgenic Nicotiana benthamiana [6,143]. In addition to the above-mentioned WRKY proteins, several members of this family identified from other plants, such as RtWRKY1 from Reaumuria trigyna [65], banana MaWRKY26 [144], and chrysanthemum DgWRKY5 [145], are also important components in abiotic stress signaling pathways.

\section{4. bZIP Transcription Factors}

The bZIP (basic leucine zipper) TF family, characterized by a highly conserved basic DNA-binding domain consisting of 16 basic amino acid residues and an adjacent dimerization motif known as leucine zipper, is extensively distributed in eukaryotes [146]. A lot of putative bZIP TFs have been identified at genome wide scale from several sequenced plant species and are categorized into three different groups.

In plants, members of bZIP TFs function in a diverse range of biological processes, including cell elongation, organ and tissue differentiation, primary root growth, flower development and seed maturation, plant senescence, and light response [147-149], as well as abiotic stress responses such as cold, high salinity, drought, and others. [150]. Especially in Arabidopsis, group A members of bZIP TFs family, including ABF1 [151], ABF2/AREB1 [152], ABF3 [153], ABF4 [154], and ABI5 [155], play important roles in ABA signal transduction and abiotic stress responses. Meanwhile, a member of group S1 bZIP factors, Arabidopsis bZIP1 has been shown to enhance salt and drought stress tolerance [156]. Hartmann et al. [157] reported that the expression of bZIP53, from group S1 bZIP TFs, was transcriptionally induced by salt treatment in Arabidopsis root and plays an important role in root metabolic reprogramming under salt stress. Similarly, transgenic alfalfa (Medicago sativa) overexpressing the Arabidopsis ABF3 TF under the control of sweet potato (Ipomoea batatas) oxidative stress-inducible SWPA2 promoter showed better growth under drought [66]. Genetic studies exhibited that OsABF1 and its closest homolog OsbZIP40 function redundantly to delay flowering time in rice under drought stress via indirect suppression of Ehd1 (Early heading date 1), encoding a key 
activator of flowering in rice, suggesting a direct connection between plant developmental program and water availability [67]. Moreover, expression of OsbZIP71 was repressed under $\mathrm{NaCl}$ treatment but, interestingly, OsbZIP71 overexpression displayed significantly high tolerance to salt stress in addition to drought and osmotic stresses. By contrast, OsbZIP71 RNAi lines showed sensitivity to salt and ABA treatment, suggesting a vital role of OsbZIP71 in ABA-mediated salt and drought stress tolerance [158]. Also, a recent study revealed that $O S A B F 1$ can enhance drought resistance in rice, probably via transcriptional activation of its target gene, COR413-TM1, encoding a putative thylakoid membrane protein [146]. Zong et al. [159] found that OsbZIP23 is the main player in rice ABA biosynthesis and drought tolerance via directly regulating the expression of numerous stress-responsive genes, such as OsPP2C49 and OsNCED4. Similarly, Dey et al. [160] identified two polymorphic forms of OsbZIP23 gene from wild rice genotypes. Functional characterization of these variants (1083 bp and 1068 bp CDS) via overexpression and gene silencing (RNAi) established that enhanced expression of OsbZIP23, instead of natural polymorphism in its coding sequence, is responsible for drought tolerance and improved grain yield in rice. Very recently, co-overexpression of the constitutively active form of OsbZIP46, along with a protein kinase (SAPK6), resulted in significantly high drought resistance [68]. Similarly, in wheat, functional analysis of a TaABL1 protein in transgenic Arabidopsis and tobacco showed that this gene is involved in accelerating stomatal closure and accumulation of osmotic substances under different stress conditions, thereby improving tolerance to multiple abiotic stresses [69]. Under cold stress, the down regulated expression of CBFs and some key COR genes in TabZIP6-overexpressing Arabidopsis seedlings led to decreased freezing tolerance [70]. Also, TabZIP60 plays an important function in multiple abiotic responses, however, enhancing plant sensitivity to abscisic acid (ABA) during seedling growth [71]. Introduction of a maize bZIP, $A B P 9$, in cotton led to reduced stomatal aperture, better root system, and higher relative water content under multiple abiotic stress conditions [72]. In tomato, the negative role of SlbZIP38 in drought and salt stress was linked to higher level of MDA and lower chlorophyll and free proline content in leaves [73]. In Eleusine coracana, transcripts of EcbZIP60 were highly induced by salt-, drought-, and methyl viologen-induced stress, and promoted abiotic stress tolerance in transgenic tobacco by activating the expression of unfolded protein-responsive pathway genes, including PDIL, CRT1, and mBiP1 [74]. Functional analysis of GmbZIP110 from soybean revealed that it can bind to the ACGT motif and modulate the expression of many stress-related genes in transgenic Arabidopsis. In addition, transgenic soybean composite seedlings and Arabidopsis exhibited enhance salt tolerance in terms of higher proline content under salt stress, indicating that GmbZIP110 acts as a positive regulator of salt stress tolerance [75]. Overexpression of a group A member of bZIP proteins, GmFDL19, significantly increased plant relative height and relative shoot dry weight at seedling stage in transgenic soybean following salt and polyethylene glycol (PEG 6000) treatments, suggesting an important role of GmFDL19 in soybean abiotic stress responses [76]. Moon et al. [77] reported that when ectopically expressed, CaBZ1 from hot pepper (Capsicum annuum) enhances dehydration tolerance in transgenic potato without any negative effect on plant growth and tuber yield. Similarly, GhABF2 from cotton has been shown to facilitate drought and salt stress tolerance in transgenic cotton through an ABA-dependent pathway, as supported by higher antioxidant enzyme activities and proline content in transgenic plants under drought and salt stress [78]. In addition, functional analysis of grape (Vitis vinifera) VvbZIP23 [161], lotus root (Nelumbo nucifera) LrbZIP [162], T. hispida ThbZIP [163], and ramie (Boehmeria nivea) BnbZIP2 [79] genes demonstrated that all these bZIP TFs play critical roles in regulating salt stress along with other abiotic stresses.

\subsection{NAC (NAM, ATAF, and CUC) Transcription Factors}

The NAC (NAM, ATAF, and CUC) proteins originally reported from petunia (Petunia hybrida) NAM [164] and Arabidopsis [165] form one of plant-specific transcription factor families. Typically, NAC family proteins are characterized by a well-conserved DNA-binding NAC domain within the $\mathrm{N}$-terminal and a highly variable transcription regulatory domain in the C-terminal, which might 
function as transcriptional activators or repressors to regulate the expression of downstream target genes [166,167].

The NAC TF family widely occurs in plants, and is multifunctional in plant growth and development, as well as in responses to abiotic stress [168]. For instance, JUB1 (JUNGBRUNNEN1), a NAC protein from Arabidopsis, was recently shown to promote dehydration tolerance under the control of both RD29A (abiotic stress-induced) and CaMV 35S (constitutive) promoters [81]. Another NAC TF gene, ATAF1, was induced by ABA treatment and high salinity. ATAF1 transgenic rice exhibited salt tolerance and insensitivity to ABA [169]. By contrast, AtNAP negatively participates in the salt stress response during seed germination and plant development via transcriptional repression of the ABA-dependent pathway-related genes (AREB1, RD20, and RD29B) [170]. Also, ANAC069-overexpressing plants displayed decreased proline biosynthesis and ROS-scavenging capability, which resulted in increased sensitivity to salt and osmotic stress [82]. Also, transcripts of GsNAC019 were upregulated in the roots of Glycine soja by less than $50 \mathrm{mM} \mathrm{NaHCO}_{3}$ conditions, and its overexpression in Arabidopsis conferred tolerance to alkaline stress during seedling and mature stages but led to reduced ABA sensitivity [83]. In rice, SNAC3 was found to modulate homeostasis of reactive oxygen species (ROS), thereby enhancing heat and drought stress tolerance [171]. ONAC022 overexpression in rice resulted in higher survival ratios and accumulated less $\mathrm{Na}^{+}$in roots and shoots in response to drought and salt stress, respectively [84]. Likewise, at flowering stage, OsNAP-overexpressing plants exhibited better yield under drought stress, in addition to enhanced tolerance against multiple abiotic stresses at the vegetative stage, without any growth retardation [172]. In wheat, under the control of a predominantly root-expressed promoter, TaRNAC1 enhanced dehydration tolerance in terms of higher biomass, grain yield, and root length [85]. Likewise, overexpression of TaNAC47 enabled plants to withstand salt, drought, and freezing stresses [86]. Furthermore, CarNAC4-a putative stress-associated TF from chickpea (Cicer arietinum)-was found to be involved in reducing water loss rates and MDA content in response to drought and salt stress, respectively [173]. MfNACsa, a lipid-anchored NAC gene from Medicago falcata, positively regulates plant drought stress tolerance through differential expression of oxidation-reduction-related, lipid transport-related, and localization-related genes [87]. In tomato, virus-induced gene silencing of SIJUB1 led to drastic reduction in plant drought tolerance, compared to control plants, and highly promoted oxidative stress [174]. Also, SINAC4-RNAi plants exhibited a higher water loss rate and lower chlorophyll content under drought and salt stress [88]. Similarly, SINAC35 is involved in promoting root growth and development under salt and drought stress in transgenic tobacco [89]. Likewise, the improved abiotic stress resistance in MlNAC9-overexpressing plants is primarily attributed to the enhanced capability to scavenge reactive oxygen species (ROS) and increased expression of stress-responsive genes through an ABA-dependent pathway [175]. In addition, sorghum SbSNAC1 [176], maize ZmNAC55 [90], and wheat TaNAC29 [177] also play positive roles in plant drought and/or salt stress tolerance. On the other hand, TaNAC2L [91] from wheat and SINAM1 [92] from tomato were reported to play important roles in heat and cold stress, respectively. By contrast, functional analysis through dominant chimeric repressor-mediated suppression revealed that ONAC095 performs opposite roles during drought and cold stress conditions in rice by acting as a positive regulator of cold response and a negative regulator of drought response [178]. Recently, An et al. [179] reported for the first time that overexpression of $M d N A C 029$, both in apple and Arabidopsis, reduces cold tolerance through the CBF-dependent pathway. Functional characterization of Pyrus betulifolia NAC TF, PbeNAC1, showed that this gene is involved in mediating drought and cold tolerance [80]. MusaNAC042-overexpressing lines of banana demonstrated high chlorophyll and lower MDA content in response to high salinity and dehydration stress, suggesting a positive role of MusaNAC042 in abiotic stress [180]. 


\subsection{Other Transcription Factors}

Several TFs from other TF families, including AP2/ERFs (APETALA2/ethylene response factor), CAMTA (calmodulin binding transcription activator), cycling Dof factor (CDF), and $\mathrm{C}_{2} \mathrm{H}_{2}-\mathrm{ZFP}$, have been reported to participate in abiotic stress responses in a variety of plants. Ectopic expression of the Arabidopsis DREB1A/CBF3 gene displayed higher photosynthetic rate and antioxidant activities in transgenic Salvia miltiorrhiza plants under drought stress [181]. Recently, Ahn et al. [182] uncovered the molecular mechanisms of dehydration tolerance in "Nipponbare", a transgenic version of rice (erf71) carrying OsERF71, and showed that erf71 strongly resists drought stress. Also, ERF6 (ETHYLENE RESPONSE FACTOR6) protein has been positively linked to ROS-signaling during plant growth, as well as biotic and abiotic stress tolerance in Arabidopsis [183]. Similarly, in Arabidopsis, members of AP2 TF family, including DREB19, DREB26, RAP2.6, and RAP2.6L, were shown to participate positively in regulating plants in response to abiotic stresses [184]. Transgenic tobacco plants overexpressing SbDREB2A from Salicornia brachiata displayed improved seed germination and growth characteristics under hyperosmotic and hyperionic stresses [185]. Likewise, SsDREB protein cloned from Suaeda salsa promoted a net photosynthesis rate in transgenic tobacco under salt and drought stress [186]. Further, CAMTA1 (calmodulin binding transcription activator) TF was found to be involved in regulating drought recovery in Arabidopsis [187]. Prasad et al. [188] reported that a member of signal responsive transcription factors, $S R 1 / C A M T A 3$, decreases salt tolerance via inhibiting the expression of salt stress-related genes. In tomato, the CDF3 gene, belonging to the cycling Dof factor (CDF) TF family, was found to be associated with higher yield and biomass production under salt stress [189]. Additionally, overexpression of TAZAT8, a member of the C2H2-ZFP family from wheat, conferred tolerance to Pi-starvation stress in tobacco by regulating ROS detoxicity and Pi acquisition [190].

\section{Potential Molecular Mechanisms of TFs in Controlling Plant Abiotic Stress Responses}

\subsection{TFs Regulating ROS Signal Transduction during Abiotic Stress Responses in Plants}

It is well known that when plant cells perceive abiotic stress stimulus via receptors or sensors, ROS accumulation significantly increases, which results in cell oxidative damage and eventually causes cell death. Recently, ROSs have been also identified as key second messengers in the complex signaling network of plant abiotic stress responses. Therefore, regulating ROS signaling and its homeostasis is an important strategy to improve stress tolerance of plants suffering from unfavorable environmental conditions [191]. As one kind of the important regulatory proteins involved in abiotic stress responses, TFs play vital roles downstream of ROS signaling pathways. Members of MYB, bHLH, WRKY, bZIP, and NAC families have been demonstrated to play important roles in regulating ROS signal transduction during abiotic stress responses in plants. For example, Mabuchi et al. reported the ROS-responsive Arabidopsis MYB30 plays a key role in regulating root growth during ROS defense responses [192]. GmMYB84, another MYB TF from soybean, also plays important roles in ROS homeostasis regulation and abiotic stress resistance in plants. Expression of GmMYB84 is induced by drought, salt, $\mathrm{H}_{2} \mathrm{O}_{2}$, and ABA. Overexpression of GmMYB84 enhanced transgenic soybean drought tolerance with higher ROS content and antioxidant enzyme activities (superoxide dismutase (SOD), peroxidase (POD), and catalase (CAT)) [30]. Ectopic expression of TaMYB33 exhibits greater ability for ROS detoxification and reconstruction of osmotic balance in Arabidopsis due to induction of AtZAT12 and AtP5CS genes, responsible for replicating the activities of ascorbate peroxidase and proline synthesis, respectively [98]. Recently, an R2R3-MYB gene, TaODORANT1, cloned from wheat was upregulated by $\mathrm{H}_{2} \mathrm{O}_{2}$ treatment, and facilitated $\mathrm{ROS}$ scavenging in transgenic tobacco via regulating CAT and SOD activities under salt and drought stress, respectively [193]. There is growing evidence that bHLH TFs facilitate ROS detoxification under abiotic stress conditions. For instance, functional characterization of NtbHLH123, a bHLH TF gene, revealed that this TF confers cold tolerance to NtbHLH123-overexpressing transgenic tobacco by regulating the NtCBF (C-repeat biding factor) pathway and ROS homeostasis [194]. Similarly, Geng and Liu demonstrated CsbHLH18 of sweet 
orange (Citrus sinenisis) also functions in modulation of cold tolerance and ROS homeostasis via regulating the antioxidant gene CsPOD [195]. Also, gain and loss of function analysis revealed that Tamarix hispida ThbHLH1 TF positively controls ROS detoxification and enhances this second messenger to mediate abiotic stress tolerance [52]. WRKY proteins govern numerous ROS-dependent abiotic stress responses through activation of the cellular antioxidant systems [57,61,64]. In groundnut (Arachis hypogaea), overexpression of MuWRKY3 promoted ROS detoxification, accompanied by increased activities of antioxidant enzymes under drought stress [196]. Similarly, Hong et al. [197] reported that maize $Z m W R K Y 4$ is required for upregulated expression and activities of ZmSOD4 and ZmcAPX under cadmium stress, indicating that ZmWRKY4 plays a vital role in controlling antioxidant defense following stress. Currently, it has been revealed by a number of research reports that NAC proteins are critically involved in escalating the antioxidant defense system under abiotic stresses. In cucumber (Cucumis sativus), CsATAF1 was recently shown to promote ROS detoxification via direct regulation of three antioxidant system genes, including CsCu-ZnSOD, CsABI5, and CsDREB2C, improving tolerance to drought stress [198]. On the other hand, TaNAC29 from wheat was reported to reduce membrane damage and $\mathrm{H}_{2} \mathrm{O}_{2}$ accumulation by enhancing the antioxidant system in plants, which finally culminates in salt stress tolerance [177].

\subsection{TFs Binding with cis-Element in the Promoters of Stress-Inducible Genes}

Transcription factors play a vital role in plant adaptation to environmental cues because of their ability to control critical downstream responses via regulating target gene expression. Entire signal transduction cascades are activated when TFs bind to diverse TF binding sites (TFBS) in the promoters of stress-inducible genes $[20-23,199]$. Therefore, a comprehensive understanding of underlying mechanisms of transcription factors and their targeted stress-inducible genes has become imperative to unravel their functionality in various abiotic stress responses. Recently, Wang et al. [30] dissected the mechanism of GmMYB84 in promoting root growth in soybean both under optimal and drought conditions and showed that overexpression of GmMYB84 results in primary root elongation under drought stress via directly binding to the MBSI motifs in the promoters of GmRBOHB-1 and GmRBOHB-2 genes, which in turn generate higher levels of $\mathrm{H}_{2} \mathrm{O}_{2}$. The rise in ROS concentration then activates the expression of genes of antioxidant enzymes SOD, CAT, and POD to scavenge ROS. In M. truncatula, Zhang et al. [108] uncovered the transcriptional regulation of C-repeat binding factor, $M t C B F 4$, under cold stress, and found that the expression of MtCBF4 is inhibited by MtMYB3 protein via binding to its promoter. Interestingly, this inhibitory effect of MtMYB3 on MtCBF4 is antagonistically relieved by $M t M Y B 61$, resulting in improved freezing tolerance and cold acclimation. It was shown that wheat TaSIM, an R2R3-MYB TF, promotes salt tolerance in Arabidopsis via binding to the MBS II motifs in the promoters of RD22 and RD29A genes, indicating that TaSIM is an upstream activator of these genes, and facilitates crosstalk between ABA-dependent and ABA-independent pathways [36]. Lee et al. [29] demonstrated that MYB96, an R2R3-type MYB protein, is responsible for integrating the ABA and cold signaling pathways in Arabidopsis by binding to the promoters of HHP (HEPTAHELICAL PROTEIN) genes, consecutively interacting with upstream CBF regulators such as ICE1, ICE2, and CAMTA3, thus facilitating their transcriptional activation in response to stressful conditions. Very recently, MdMYB88 and MdMYB124 were found to modulate the expression of cold-responsive genes MdCSP3 and MdCCA1 through binding to the AACCG motifs in their promoters under cold stress and increase cold hardiness both in apple and Arabidopsis [41]. Wei et al. [112] revealed that chicory CiMYB3 and CiMYB5 proteins contribute to the orchestration of fructan degradation under abiotic stress and hormonal treatments by recognizing the MYB-core motifs (C/TNGTTA/G) in the promoters of fructan 1-exohydrolase (1-FEH) genes. Similarly, OsMYBR1 was found to contain a cis-acting sequence, ABRE, in its promoter, and to confer dehydration tolerance to transgenic Arabidopsis via induction of stress-responsive genes such as OsProt, OsLEA3, OsP5CS, and OsRab16 [103]. Yeast one-hybrid screening showed that OsPIF14, a putative phytochrome-interacting bHLH TF, binds to the promoter of cold-responsive OsDREB1B TF 
thereby represses its expression through an extended N-box, suggesting their involvement in crosstalk between light and stress signaling [200]. In Arabidopsis, WRKY71 functions antagonistically against salt-induced late flowering by regulating LFY (LEAFY) and FT (FLOWERING LOCUS T) genes [56]. Under salt stress, RtWRKY1 increases the expression of proline biosynthesis (AtP5CS1 and AtP5CS2) genes in $\mathrm{WT}$, and AtSOS1 in transgenics, which in turn regulate $\mathrm{Na}^{+}$extrusion in response to salt stress, indicating that RtWRKY1 promotes the osmoregulatory capacity of transgenics via induction of $\mathrm{Na}^{+}$ extrusion and proline biosynthesis [65]. Zong et al. [159] reported that OsbZIP23 is transcriptionally activated via interacting with SAPK2 (Suc nonfermenting-1-related protein kinase2), which in turn interacts with an ABI1 homolog, OsPP2C49, resulting in the inhibition of OsbZIP23 activity. Further, OsbZIP23 can directly regulate OsNCED4 (ABA biosynthesis) and OsPP2C49 genes, suggesting that OsbZIP23 is involved in feedback regulation of ABA biosynthesis and signaling, as well as drought tolerance, in rice. TabZIP6 protein negatively regulates freezing tolerance through the downregulated expression of CBF1, CBF3, and some COR genes in transgenic Arabidopsis [70]. VaNAC26 from Vitis amurensis was reported to participate in transcriptional regulation of JA (jasmonic acid) synthesis, and signaling genes including AOC1, LOX2, PDF1.2, VSP1, and MYC2 via binding to NACRS motifs in their promoters thus impart drought tolerance [93]. In Arabidopsis, ANAC069 inhibited the expression of proline biosynthesis (P5CS) and antioxidant (POD, SOD, and GST) genes under salt stress via binding to $C[A / G] C G[T / G]$ sequences in their promoters, which led to enhanced salt and osmotic stress sensitivity [82]. MdNAC029, cloned from apple, binds to the promoters of MdCBF1 and MdCBF4 genes, thereby repressing their transcript levels that lead to reduced cold tolerance [179].

\subsection{The Significance of Protein-Protein Interactions}

Recent developments in molecular biology have shown that proteins very often establish combinatorial interactions with each other, rather than acting alone, to carry out their complex biological functions [201]. In general, the term "protein-protein interactions" refers to the association of two or more protein molecules binding together and comprises a range of events, like functional and physical interactions, as well as transient and permanent complexes [202] (Figure 2). The coordination of protein-protein interactions (PPIs) mostly mediates the overall molecular architecture, both structurally and functionally in all organisms. The majority of cellular processes is dictated by protein-protein interactions and is thought to participate in governing responses of organisms under different environments, including stress conditions (Figure 2). 


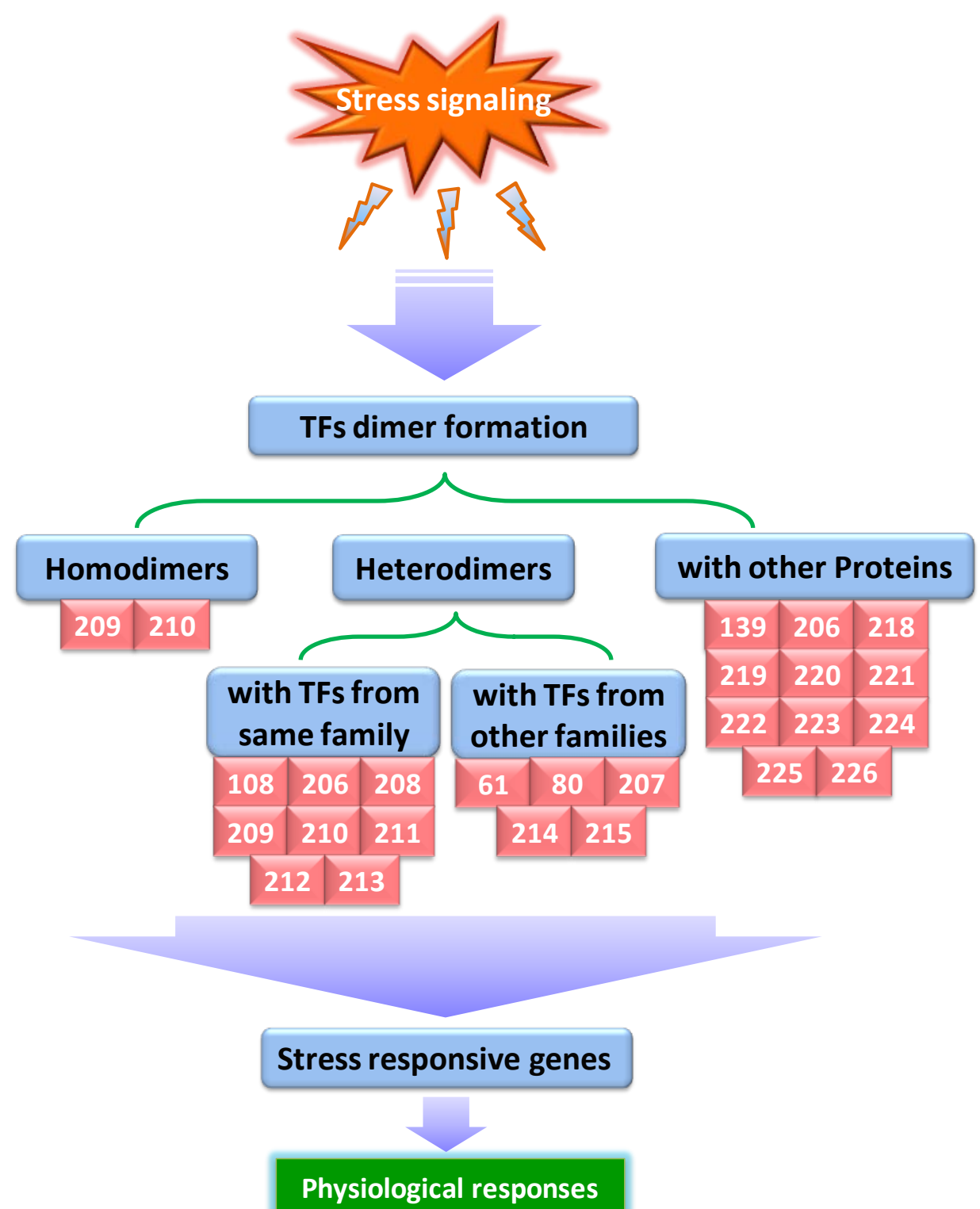

Figure 2. Model for dimer formation of transcription factors during abiotic stress responses. Numbers in red square boxes represent corresponding references.

It has been well established that a significant level of crosstalk exists between the signal transduction pathways during abiotic stress conditions involving two or more TFs [203]. A bulk of TFs can form homodimers or heterodimers through physical interactions with an identical protein or other members of the same family, respectively, or establish complexes with TFs from other protein families [204], offering huge combinatorial flexibility during the regulation of transcription [205]. In plants, intra- and interfamily TF interactions have been widely studied during the last decades. Here, we discuss the recent understandings of TF interactions and their functions during abiotic stress tolerance. Using yeast two-hybrid ( $\mathrm{Y} 2 \mathrm{H})$ and bimolecular fluorescence complementation (BiFC) assays, Zhang et al. [108] reported that MtMYB3 interacts with MtMYB61 in M. truncatula and this interaction in turn results in relieving the inhibitory effect of MtMYB3 on the expression of a C-repeat binding factor, $M t C B F 4$, conferring freezing tolerance. Likewise, stress-responsive MYB TFs, MYBR1 and MYBR2, physically interact with each other and are partially redundant in their functions, as indicated by senescence and stress-related phenotypes of double mutant mybr1mybr 2 that are stronger than single 
mybr1 and mybr2 mutants [206]. Also, in soybean, the interaction of GmMYB174 with GmWRKY27 protein suppresses the expression of a downstream target gene, GmNAC29, which acts as a negative effector of stress tolerance, conferring drought stress tolerance [61]. Deng et al. [207] revealed that physical interaction of two basic helix-loop-helix TFs, OsICE1 and OsICE2, with OsMYBS3 TF, promotes cold tolerance in rice. Also according to Feng et al. [208], physical interaction between O11, a bHLH TF, and ZmICE1 TF in maize leads to the integration of stress responses and endosperm development. In recent times, Wang et al. [209] demonstrated that ThWRKY4 from Tamarix hispida is a dimeric protein that can form both homodimers via self-interaction and heterodimers with ThWRKY2 and ThWRKY3 to regulate abiotic stress responses. Similarly, two other WRKY proteins from walnut (Juglans regia), JrWRKY2 and JrWRKY7, both were found to form homodimers and can also interact with each other to mediate seed development and abiotic stress responses [210]. Additionally, functional interactions among WRKY25, WRKY26, and WRKY33 proteins promote heat stress tolerance in Arabidopsis via cooperative regulation of heat shock proteins related and ethylene-activated signaling pathways [211]. Further, yeast two-hybrid experiments confirmed that Arabidopsis WRKY6 can interact with WRKY42, and both proteins act in plant Pi-deficient environments by repressing the transcription of PHO1 (PHOSPHATE1) via binding to W-box motifs in its promoter [212]. In wheat, co-expression of drought-responsive $\gamma$-clade HD-Zip I TF genes, TaHDZipI-3, TaHDZipI-4, and TaHDZipI-5, in the same tissue, in addition to their ability to heterodimerize, suggests their role in wheat response to water deficit [213]. PbeNAC1, cloned from Pyrus betulifolia, enhances the transcript levels of stress-responsive genes through physical interaction with PbeDREB1 and PbeDREB2A TF proteins, thereby mediating cold and drought stress tolerance in transgenic tobacco [80]. In peanut (Arachis hypogaea), the AhAREB1/AhNAC2 protein complex leads to inhibition of AhNCED1 expression under drought stress and acts as a negative feedback regulator of ABA biosynthesis [214]. Likewise, Shan et al. [215] described that a cold-inducible MaNAC1 TF from banana is not only a direct target of MaICE1, but also physically interacts with MaCBF1, indicating that MaNAC1 regulates cold stress tolerance through its interaction with ICE1-CBF cold-signaling pathway. Overall, these studies provide helpful insights into TF interaction events and define their roles in plant abiotic stress responses.

Functional modulation of transcription factors via interactions with regulatory proteins is an important step in the regulation of signal transduction pathways [216,217]. Recently, several research studies have established that interactions between TFs with their interacting partners (proteins) have a significant role in mediating abiotic stress tolerance in plants $[218,219]$. For example, in chickpea, two putative transcription factors, Myb.Ph and Athb-1, bind to the promoter of a stress-responsive ferritin protein, CaFer1; in addition, CaFer1 interacts with iron transporter IRT1, and the resulting ferritin1-complex then mediates iron homeostasis and drought stress tolerance [218]. A CCA1-like MYB protein, GmMYB138a, interacts with GmSGF14l (a 14-3-3 protein) that alters the subcellular localization of GmMYB138a. qPCR analysis demonstrated that GmMYB138a and GmSGF141 respond synergistically or antagonistically to salt, drought, and cold stresses [220]. In addition, Jaradat et al. [206] stated that Arabidopsis MYBR1 physically interacts with an ABA receptor protein, PYL8, and directly participates in early ABA signaling. Moreover, Li et al. [221] also identified AtMYB44 as an interacting partner of RCAR1/PYL9 protein, an ABA receptor, and showed that this interaction reduces the inhibitory effect of RCAR1/PYL9 on ABI1 activity, implying that AtMYB44 negatively regulates ABA signaling. Using yeast two hybridization and CoIP approaches, recently, Zhou et al. [222] screened out a small ubiquitin-like modifier E3 ligase MdSIZ1 as an interacting protein of MdMYB1 that enhances anthocyanin accumulation in apple under low temperature via sumoylation of MdMYB1 protein. Using both GST-pulldown and BiFC assays, Wang et al. [223] disclosed that CgbHLH001 from Chenopodium glaucum is a potential interaction component of CgCDPK protein in the signal transduction pathway in response to drought or salt stress. In Arabidopsis, the interaction of WRKY8, a positive regulator of salt stress, with VQ9 (a VQ motif-containing protein) in the nucleus, decreases the DNA-binding activity of WRKY8, resulting in modulation of salt stress 
tolerance [224]. $\mathrm{Y} 2 \mathrm{H}$ assay revealed that direct interaction of rice OsWRKY30 with OsMPK3 protein causes phosphorylation of OsWRKY30, leading to improved drought tolerance [139]. In rice, interaction of MODD (Mediator of OsbZIP46 deactivation and degradation, a homolog of AFP) protein with OsbZIP46 through the D domain upsets the regulation of ABA signaling and drought tolerance [225]. Using the $\mathrm{Y} 2 \mathrm{H}$ system, Vivek et al. [219] identified NAC TF as an interacting partner of ZoCDPK1 (Zingiber officinale Calcium-dependent protein kinase 1) and showed that ZoCDPK1 operates in ginger through NAC-mediated, ABA-independent, cold nonresponsive stress signaling pathway. Similarly, the physical interaction of late embryogenesis abundant (LEA) protein, GmLEA3.1, with soybean GmDi19-5, a member of zinc finger TF family, enhances the stability of the GmDi19-5 protein and promotes abiotic stress sensitivity in transgenic Arabidopsis lines [226].

These studies indicate that protein-protein interactions play vital roles in abiotic stress responses and offer critical understanding of the regulation of abiotic stress responses. Particularly, this approach is helpful in crop species with narrow mutant stocks, in which it is hard to set up gene interaction relationships via epistasis. Further, it can recognize proteins that might not be detected by changes in their mRNA transcript levels, in addition to the direct interaction partners of regulatory proteins [227]. Hence, protein-protein interaction studies provide a novel perspective to perceive their role in a cell and to understand molecular mechanisms that trigger appropriate plant responses under abiotic stress.

\section{Conclusion and Future Perspectives}

Abiotic stress signal cascades engage different TFs to regulate the expression of stress-responsive genes, thereby imparting stress tolerance to plants. The current research progress on the involvement of TFs in conferring abiotic stress tolerance under stress conditions highlight their fundamental job in plant growth and development. This review about the TF families discussed above indicates that plenty of transcription factors play important roles in abiotic stress tolerance, whose applications are likely to make a great improvement in crop breeding. However, understanding their functions and interactions is still insufficient and there are some difficulties ahead which must be overcome for the effective implementation of manipulating TFs to genetic engineering breeding. Firstly, functional redundancy among some TFs makes it difficult to notice mutations in single mutants. Nevertheless, the functional redundancy genes should be knocked out at the same time using the new high-efficient technique, CRISPR-Cas9-mediated genome editing [228]. Likewise, reverse-genetics approaches are also useful for breaking through this problem. For example, the creation of dominant negative mutants via binding repressor domains to transcription factors seems to be an alternative option [229]. Secondly, plants are simultaneously subjected to different abiotic stress conditions in nature. In order to survive in such environments, multiple genes and different stress response pathways are co-activated [230], resulting most likely in a synergistic or antagonistic effect on each other. In addition, owing to the complexity of regulating networks among different TFs at different levels, overexpression of certain transcription factors might affect other signaling pathways. For example, in an Arabidopsis mutant, overexpression of AtMYB96 promotes dehydration tolerance but significantly reduces lateral root formation, probably due to multiple drought stress-signaling pathways and/or functional redundancy of multiple MYB proteins controlling lateral root formation [231]. Therefore, in future, a comprehensive understanding of regulatory networks and complete elucidation of transcription factors is direly needed if we wish to use regulatory genes as a molecular leverage to raise multiple stress-resistant crop varieties. Thirdly, TF research should be primarily focused on the identification and characterization of multiple stresses-responsive TF genes. Moreover, we should also examine the molecular effects of overexpressing TFs, in addition to conducting stress tolerance assays. In some cases, the constitutive overexpression of TF genes, although endowing transgenic plants with stress tolerance, results in growth and development defects, such as growth retardation, leaf senescence, and lower yields. This problem should be overcome through screening and applying of tissue-specific promoters, such as an epidermis-specific CER6 promoter [232] and stress-inducible promoters like $r d 29 A$ [233]. Additionally, despite the many studies on glycophytes, such as Arabidopsis, rice, and wheat, 
knowledge about xerophytes and halophytes is considerably limited. Given that xerophytic and halophytic species living in arid and saline regions contain abundant stress-resistant genes and have evolved specialized strategies to survive in harsh environments [234,235], to identify these key genes and understand the functional mechanisms of the naturally tolerant species will contribute to developing stress tolerance in crops. In conclusion, although genome-wide analysis has identified a great deal of TFs associated with stress tolerance, nevertheless, their functional validity, crosstalk, and interactions during abiotic stress require further, deeper understanding. In-depth knowledge about a large number of TFs and their downstream target genes can provide better elucidation of regulatory mechanisms involved in plant abiotic stress tolerance progress, which supports acquiring ideal candidate TF genes and developing strategies for generating stress-tolerant crops with higher qualities and yields.

Acknowledgments: This work has been jointly supported by the National Natural Science Foundation of China (grant No. 051160006 and 31730093), and the National Basic Research Program of China (973 Program, grant no. 2014CB138701).

Conflicts of Interest: The authors declare no conflict of interest.

\section{References}

1. McGuire, S. The state of food insecurity in the world 2015. In Meeting the 2015 International Hunger Targets: Taking Stock of Uneven Progress; Food and Agriculture Organization (FAO): Rome, Italy, 2015; Volume 6, pp. 623-624.

2. Shabala, S.; Bose, J.; Hedrich, R. Salt bladders: Do they matter? Trends Plant Sci. 2014, 19, 687-691. [CrossRef] [PubMed]

3. Bruinsma, J. The resource outlook to: By how much do land, water and crops yields need to increase by 2050? In Prepared for the FAO Expert Meeting on 'How to Feed the World in 2050'; Food and Agriculture Organization (FAO): Rome, Italy, 2009; pp. 1-33.

4. Boyer, J.S. Plant productivity and environment. Science 1982, 218, 443-448. [CrossRef] [PubMed]

5. Guttikonda, S.K.; Valliyodan, B.; Neelakandan, A.K.; Tran, L.S.; Kumar, R.; Quach, T.N.; Voothuluru, P.; Gutierrez-Gonzalez, J.J.; Aldrich, D.L.; Pallardy, S.G.; et al. Overexpression of AtDREB1D transcription factor improves drought tolerance in soybean. Mol. Biol. Rep. 2014, 41, 7995-8008. [CrossRef] [PubMed]

6. Chu, X.; Wang, C.; Chen, X.; Lu, W.; Li, H.; Wang, X.; Hao, L.; Guo, X. The cotton WRKY gene GhWRKY41 positively regulates salt and drought stress tolerance in transgenic Nicotiana benthamiana. PLoS ONE 2015, 10, e0143022. [CrossRef] [PubMed]

7. Yamaguchi, K.; Takahashi, Y.; Berberich, T.; Imai, A.; Takahashi, T.; Michael, A.J.; Kusano, T.A. A protective role for the polyamine spermine against drought stress in Arabidopsis. Biochem. Biophys. Res. Commun. 2007, 352, 486-490. [CrossRef] [PubMed]

8. Kitsios, G.; Doonan, J.H. Cyclin dependent protein kinases and stress responses in plants. Plant Signal. Behav. 2011, 6, 204-209. [CrossRef] [PubMed]

9. Peleg, Z.; Blumwald, E. Hormone balance and abiotic stress tolerance in crop plants. Curr. Opin. Plant Biol. 2011, 14, 290-295. [CrossRef] [PubMed]

10. Liu, J.; Osbourn, A.; Ma, P. MYB transcription factors as regulators of phenylpropanoid metabolism in plants. Mol. Plant. 2015, 8, 689-708. [CrossRef] [PubMed]

11. Zwack, P.J.; Rashotte, A.M. Interactions between Cytokinin signalling and abiotic stress responses. J. Exp. Bot. 2015, 66, 4863-4871. [CrossRef] [PubMed]

12. Ma, Y.; Dai, X.; Xu, Y.; Luo, W.; Zheng, X.; Zeng, D.; Pan, Y.; Lin, X.; Liu, H.; Zhang, D.; et al. Cold1 confers chilling tolerance in rice. Cell 2015, 160, 1209-1221. [CrossRef] [PubMed]

13. Yuan, F.; Yang, H.; Xue, Y.; Kong, D.; Ye, R.; Li, C.; Zhang, J.; Theprungsirikul, L.; Shrift, T.; Krichilsky, B.; et al. OSCA1 mediates osmotic-stress-evoked $\mathrm{Ca}^{2+}$ increases vital for osmosensing in Arabidopsis. Nature 2014, 514, 367-371. [CrossRef] [PubMed]

14. Hamilton, E.S.; Jensen, G.S.; Maksaev, G.; Katims, A.; Sherp, A.M.; Haswell, E.S. Mechanosensitive channel MSL8 regulates osmotic forces during pollen hydration and germination. Science 2015, 350, 438-441. [CrossRef] [PubMed] 
15. Swarbreck, S.M.; Colaco, R.; Davies, J.M. Plant calcium-permeable channels. Plant Physiol. 2013, 163, 514-522. [CrossRef] [PubMed]

16. Kacperska, A. Sensor types in signal transduction pathways in plant cells responding to abiotic stressors: Do they depend on stress intensity? Physiol. Plant. 2004, 122, 159-168. [CrossRef]

17. Torres, M.A.; Dangl, J.L. Functions of the respiratory burst oxidase in biotic interactions, abiotic stress and development. Curr. Opin. Plant Biol. 2005, 8, 397-403. [CrossRef] [PubMed]

18. Asai, T.; Tena, G.; Plotnikova, J.; Willmann, M.R.; Chiu, W.L.; Gomez-Gomez, L.; Boller, T.; Ausubel, F.M.; Sheen, J. Map kinase signalling cascade in Arabidopsis innate immunity. Nature 2002, 415, 977-983. [CrossRef] [PubMed]

19. D'Autreaux, B.; Toledano, M.B. ROS as signalling molecules: Mechanisms that generate specificity in ROS homeostasis. Nat. Rev. Mol. Cell Biol. 2007, 8, 813-824. [CrossRef] [PubMed]

20. Hu, W.; Huang, C.; Deng, X.; Zhou, S.; Chen, L.; Li, Y.; Wang, C.; Ma, Z.; Yuan, Q.; Wang, Y.; et al. TaASR1, a transcription factor gene in wheat, confers drought stress tolerance in transgenic tobacco. Plant Cell Environ. 2013, 36, 1449-1464. [CrossRef] [PubMed]

21. Liu, W.; Tai, H.; Li, S.; Gao, W.; Zhao, M.; Xie, C.; Li, W.X. bHLH122 is important for drought and osmotic stress resistance in Arabidopsis and in the repression of ABA catabolism. New Phytol. 2014, 201, 1192-1204. [CrossRef] [PubMed]

22. Saibo, N.J.; Lourenco, T.; Oliveira, M.M. Transcription factors and regulation of photosynthetic and related metabolism under environmental stresses. Ann. Bot. 2009, 103, 609-623. [CrossRef] [PubMed]

23. Nakashima, K.; Ito, Y.; Yamaguchi-Shinozaki, K. Transcriptional regulatory networks in response to abiotic stresses in Arabidopsis and grasses. Plant Physiol. 2009, 149, 88-95. [CrossRef] [PubMed]

24. Gao, F.; Zhou, J.; Deng, R.Y.; Zhao, H.X.; Li, C.L.; Chen, H.; Suzuki, T.; Park, S.U.; Wu, Q. Overexpression of a Tartary Buckwheat R2R3-MYB transcription factor gene, FtMYB9, enhances tolerance to drought and salt stresses in transgenic Arabidopsis. J. Plant Physiol. 2017, 214, 81-90. [CrossRef] [PubMed]

25. Yadav, N.; Taunk, J.; Rani, A.; Aneja, B.; Yadav, R.C. Role of transcription factors in abiotic stress tolerance in crop plants. Clim. Chang. Plant Abiotic Stress Toler. 2011, 605-640. [CrossRef]

26. Seo, P.; Jung, J.; Park, C. Transcription factors: Improving abiotic stress tolerance in plants. Improv. Crop Resist. Abiotic Stress 2012, 451-479. [CrossRef]

27. Cominelli, E.; Galbiati, M.; Tonelli, C. Transcription factors controlling stomatal movements and drought tolerance. Transcription 2010, 1, 41-45. [CrossRef] [PubMed]

28. Ramalingam, A.; Kudapa, H.; Pazhamala, L.T.; Garg, V.; Varshney, R.K. Gene expression and yeast two-hybrid studies of 1R-MYB transcription factor mediating drought stress response in chickpea (Cicer arietinum L.). Front. Plant Sci. 2015, 6, 1117. [CrossRef] [PubMed]

29. Lee, H.G.; Seo, P.J. The MYB96-HHP module integrates cold and abscisic acid signaling to activate the CBF-COR pathway in Arabidopsis. Plant J. 2015, 82, 962-977. [CrossRef] [PubMed]

30. Wang, N.; Zhang, W.; Qin, M.; Li, S.; Qiao, M.; Liu, Z.; Xiang, F. Drought tolerance conferred in soybean (Glycine max. L.) by GmMYB84, a novel R2R3-MYB transcription factor. Plant Cell Physiol. 2017, 58, 1764-1776. [CrossRef] [PubMed]

31. Li, X.W.; Wang, Y.; Yan, F.; Li, J.W.; Zhao, Y.; Zhao, X.; Zhai, Y.; Wang, Q.Y. Overexpression of Soybean R2R3-MYB transcription factor, GmMYB12B2, and tolerance to UV radiation and salt stress in transgenic Arabidopsis. Genet. Mol. Res. 2016, 15, 1-10. [CrossRef] [PubMed]

32. Casaretto, J.A.; El-kereamy, A.; Zeng, B.; Stiegelmeyer, S.M.; Chen, X.; Bi, Y.M.; Rothstein, S.J. Expression of OsMYB55 in maize activates stress-responsive genes and enhances heat and drought tolerance. BMC Genom. 2016, 17, 312. [CrossRef] [PubMed]

33. Wang, R.; Jing, W.; Xiao, L.; Jin, Y.; Shen, L.; Zhang, W. The rice high-affinity potassium transporter1; 1 is involved in salt tolerance and regulated by an MYB-type transcription factor. Plant Physiol. 2015, 168, 1076-1090. [CrossRef] [PubMed]

34. Guo, C.; Yao, L.; You, C.; Wang, S.; Cui, J.; Ge, X.; Ma, H. MID1 plays an important role in response to drought stress during reproductive development. Plant J. 2016, 88, 280-293. [CrossRef] [PubMed]

35. Zhu, N.; Cheng, S.; Liu, X.; Du, H.; Dai, M.; Zhou, D.X.; Yang, W.; Zhao, Y. The R2R3-type MYB gene OsMYB91 has a function in coordinating plant growth and salt stress tolerance in rice. Plant Sci. 2015, 236, 146-156. [CrossRef] [PubMed] 
36. Yu, Y.; Ni, Z.; Chen, Q.; Qu, Y. The wheat salinity-induced R2R3-MYB transcription factor TaSIM confers salt stress tolerance in Arabidopsis thaliana. Biochem. Biophys. Res. Commun. 2017, 491, 642-648. [CrossRef] [PubMed]

37. Dong, W.; Song, Y.; Zhao, Z.; Qiu, N.W.; Liu, X.; Guo, W. The Medicago truncatula R2R3-MYB transcription factor gene MtMYBS1 enhances salinity tolerance when constitutively expressed in Arabidopsis thaliana. Biochem. Biophys. Res. Commun. 2017, 490, 225-230. [CrossRef] [PubMed]

38. Campos, J.F.; Cara, B.; Perez-Martın, F.; Pineda, B.; Egea, I.; Flores, F.B.; Fernandez-Garcia, N.; Cape, J.; Moreno, V.; Angosto, T.; et al. The tomato mutant ars1 (altered response to salt stress 1) identifies an R1-type MYB transcription factor involved in stomatal closure under salt acclimation. Plant Biotechnol. J. 2016, 14, 1345-1356. [CrossRef] [PubMed]

39. Butt, H.I.; Yang, Z.; Chen, E.; Zhao, G.; Gong, Q.; Yang, Z.; Zhang, X.; Li, F. Functional characterization of cotton GaMYB62L, a novel R2R3 TF in transgenic Arabidopsis. PLoS ONE 2017, 12, e0170578. [CrossRef] [PubMed]

40. Butt, H.I.; Yang, Z.; Gong, Q.; Chen, E.; Wang, X.; Zhao, G.; Ge, X.; Zhang, X.; Li, F. GaMYB85, an R2R3 MYB gene, in transgenic Arabidopsis plays an important role in drought tolerance. BMC Plant Biol. 2017, 17, 142. [CrossRef] [PubMed]

41. Xie, Y.; Chen, P.; Yan, Y.; Bao, C.; Li, X.; Wang, L.; Shen, X.; Li, H.; Liu, X.; Niu, C.; et al. An atypical R2R3 MYB transcription factor increases cold hardiness by CBF-dependent and CBF-independent pathways in apple. New Phytol. 2018, 218, 201-218. [CrossRef] [PubMed]

42. Shen, X.; Guo, X.; Guo, X.; Zhao, D.; Zhao, W.; Chen, J.; Li, T. PacMYBA, a sweet cherry R2R3-MYB transcription factor, is a positive regulator of salt stress tolerance and pathogen resistance. Plant Physiol. Biochem. 2017, 112, 302-311. [CrossRef] [PubMed]

43. Le Hir, R.; Castelain, M.; Chakraborti, D.; Moritz, T.; Dinant, S.; Bellini, C. AtbHLH68 transcription factor contributes to the regulation of ABA homeostasis and drought stress tolerance in Arabidopsis thaliana. Physiol. Plant 2017, 160, 312-327. [CrossRef] [PubMed]

44. Dong, Y.; Wang, C.; Han, X.; Tang, S.; Liu, S.; Xia, X.; Yin, W. A novel bHLH transcription factor PebHLH35 from Populus euphratica confers drought tolerance through regulating stomatal development, photosynthesis and growth in Arabidopsis. Biochem. Biophys. Res. Commun. 2014, 450, 453-458. [CrossRef] [PubMed]

45. Liu, Y.; Ji, X.; Nie, X.; Qu, M.; Zheng, L.; Tan, Z.; Zhao, H.; Huo, L.; Liu, S.; Zhang, B.; et al. Arabidopsis AtbHLH112 regulates the expression of genes involved in abiotic stress tolerance by binding to their E-box and GCG-box motifs. New Phytol. 2015, 207, 692-709. [CrossRef] [PubMed]

46. Chen, H.C.; Hsieh-Feng, V.; Liao, P.C.; Cheng, W.H.; Liu, L.Y.; Yang, Y.W.; Lai, M.H.; Chang, M.C. The function of OsbHLH068 is partially redundant with its homolog, AtbHLH112, in the regulation of the salt stress response but has opposite functions to control flowering in Arabidopsis. Plant Mol. Biol. 2017, 94, 531-548. [CrossRef] [PubMed]

47. Zhai, Y.; Zhang, L.; Xia, C.; Fu, S.; Zhao, G.; Jia, J.; Kong, X. The wheat transcription factor, TabHLH39, improves tolerance to multiple abiotic stressors in transgenic plants. Biochem. Biophys. Res. Commun. 2016, 473, 1321-1327. [CrossRef] [PubMed]

48. Yao, P.; Sun, Z.; Li, C.; Zhao, X.; Li, M.; Deng, R.; Huang, Y.; Zhao, H.; Chen, H.; Wu, Q. Overexpression of Fagopyrum tataricum FtbHLH2 enhances tolerance to cold stress in transgenic Arabidopsis. Plant Physiol. Biochem. 2018, 125, 85-94. [CrossRef] [PubMed]

49. Yao, P.-F.; Li, C.-L.; Zhao, X.-R.; Li, M.-F.; Zhao, H.-X.; Guo, J.-Y.; Cai, Y.; Chen, H.; Wu, Q. Overexpression of a tartary buckwheat gene, FtbHLH3, enhances drought/oxidative stress tolerance in transgenic Arabidopsis. Front. Plant Sci. 2017, 8, 625. [CrossRef] [PubMed]

50. Qiu, Z.; Wang, X.; Gao, J.; Guo, Y.; Huang, Z.; Du, Y. The tomato Hoffman's Anthocyaninless gene encodes a bHLH transcription factor involved in anthocyanin biosynthesis that is developmentally regulated and induced by low temperatures. PLoS ONE 2016, 11, e0151067. [CrossRef] [PubMed]

51. Jin, C.; Huang, X.S.; Li, K.Q.; Yin, H.; Li, L.T.; Yao, Z.H.; Zhang, S.L. Overexpression of a bHLH1 transcription factor of Pyrus ussuriensis confers enhanced cold tolerance and increases expression of stress-responsive genes. Front. Plant Sci. 2016, 7, 441. [CrossRef] [PubMed]

52. Ji, X.; Nie, X.; Liu, Y.; Zheng, L.; Zhao, H.; Zhang, B.; Huo, L.; Wang, Y. A bHLH gene from Tamarix hispida improves abiotic stress tolerance by enhancing osmotic potential and decreasing reactive oxygen species accumulation. Tree Physiol. 2016, 36, 193-207. [PubMed] 
53. Yang, T.; Hao, L.; Yao, S.; Zhao, Y.; Lu, W.; Xiao, K. TaBHLH1, a bHLH-type transcription factor gene in wheat, improves plant tolerance to pi and $\mathrm{n}$ deprivation via regulation of nutrient transporter gene transcription and ROS homeostasis. Plant Physiol. Biochem. 2016, 104, 99-113. [CrossRef] [PubMed]

54. Huang, D.; Dai, W. Molecular characterization of the basic helix-loop-helix (bHLH) genes that are differentially expressed and induced by iron deficiency in Populus. Plant Cell Rep. 2015, 34, 1211-1224. [CrossRef] [PubMed]

55. Raineri, J.; Wang, S.; Peleg, Z.; Blumwald, E.; Chan, R.L. The rice transcription factor OsWRKY47 is a positive regulator of the response to water deficit stress. Plant Mol. Biol. 2015, 88, 401-413. [CrossRef] [PubMed]

56. Yu, Y.; Wang, L.; Chen, J.; Liu, Z.; Park, C.M.; Xiang, F. WRKY71 acts antagonistically against salt-delayed flowering in Arabidopsis thaliana. Plant Cell Physiol. 2018, 59, 414-422. [CrossRef] [PubMed]

57. Sun, Y.; Yu, D. Activated expression of AtWRKY53 negatively regulates drought tolerance by mediating stomatal movement. Plant Cell Rep. 2015, 34, 1295-1306. [CrossRef] [PubMed]

58. Cai, R.; Dai, W.; Zhang, C.; Wang, Y.; Wu, M.; Zhao, Y.; Ma, Q.; Xiang, Y.; Cheng, B. The maize WRKY transcription factor ZmWRKY17 negatively regulates salt stress tolerance in transgenic Arabidopsis plants. Planta 2017, 246, 1215-1231. [CrossRef] [PubMed]

59. Kim, C.-Y.; Vo, K.T.X.; Nguyen, C.D.; Jeong, D.-H.; Lee, S.-K.; Kumar, M.; Kim, S.-R.; Park, S.-H.; Kim, J.-K.; Jeon, J.-S. Functional analysis of a cold-responsive rice WRKY gene, OsWRKY71. Plant Biotechnol. Rep. 2016, 10, 13-23. [CrossRef]

60. Ma, J.; Gao, X.; Liu, Q.; Shao, Y.; Zhang, D.; Jiang, L.; Li, C. Overexpression of TaWRKY146 increases drought tolerance through inducing stomatal closure in Arabidopsis thaliana. Front. Plant Sci. 2017, 8, 2036. [CrossRef] [PubMed]

61. Wang, F.; Chen, H.W.; Li, Q.T.; Wei, W.; Li, W.; Zhang, W.K.; Ma, B.; Bi, Y.D.; Lai, Y.C.; Liu, X.L.; et al. GmWRKY27 interacts with GmMYB174 to reduce expression of GmNAC29 for stress tolerance in soybean plants. Plant J. 2015, 83, 224-236. [CrossRef] [PubMed]

62. Hichri, I.; Muhovski, Y.; Zizkova, E.; Dobrev, P.I.; Gharbi, E.; Franco-Zorrilla, J.M.; Lopez-Vidriero, I.; Solano, R.; Clippe, A.; Errachid, A.; et al. The Solanum lycopersicum WRKY3 transcription factor SIWRKY3 is involved in salt stress tolerance in tomato. Front. Plant Sci. 2017, 8, 1343. [CrossRef] [PubMed]

63. Liu, L.; Zhang, Z.; Dong, J.; Wang, T. Overexpression of MtWRKY76 increases both salt and drought tolerance in Medicago truncatula. Environ. Exp. Bot. 2016, 123, 50-58. [CrossRef]

64. Ullah, A.; Sun, H.; Yang, X.; Zhang, X. A novel cotton WRKY gene, GhWRKY6-like, improves salt tolerance by activating the ABA signaling pathway and scavenging of reactive oxygen species. Physiol. Plant. 2017, 162, 439-454. [CrossRef] [PubMed]

65. Du, C.; Zhao, P.; Zhang, H.; Li, N.; Zheng, L.; Wang, Y. The Reaumuria trigyna transcription factor RtWRKY1 confers tolerance to salt stress in transgenic Arabidopsis. J. Plant Physiol. 2017, 215, 48-58. [CrossRef] [PubMed]

66. Wang, Z.; Su, G.; Li, M.; Ke, Q.; Kim, S.Y.; Li, H.; Huang, J.; Xu, B.; Deng, X.P.; Kwak, S.-S. Overexpressing Arabidopsis $A B F 3$ increases tolerance to multiple abiotic stresses and reduces leaf size in alfalfa. Plant Physiol. Biochem. 2016, 109, 199-208. [CrossRef] [PubMed]

67. Zhang, C.; Liu, J.; Zhao, T.; Gomez, A.; Li, C.; Yu, C.; Li, H.; Lin, J.; Yang, Y.; Liu, B.; et al. A drought-inducible transcription factor delays reproductive timing in rice. Plant Physiol. 2016, 171, 334-343. [CrossRef] [PubMed]

68. Chang, Y.; Nguyen, B.H.; Xie, Y.; Xiao, B.; Tang, N.; Zhu, W.; Mou, T.; Xiong, L. Co-overexpression of the constitutively active form of OsbZIP46 and ABA-activated protein kinase SAPK6 improves drought and temperature stress resistance in rice. Front. Plant Sci. 2017, 8, 1102. [CrossRef] [PubMed]

69. Xu, D.B.; Gao, S.Q.; Ma, Y.Z.; Xu, Z.S.; Zhao, C.P.; Tang, Y.M.; Li, X.Y.; Li, L.C.; Chen, Y.F.; Chen, M. ABI-like transcription factor gene TaABL1 from wheat improves multiple abiotic stress tolerances in transgenic plants. Funct. Integr. Genom. 2014, 14, 717-730. [CrossRef] [PubMed]

70. Cai, W.; Yang, Y.; Wang, W.; Guo, G.; Liu, W.; Bi, C. Overexpression of a wheat (Triticum aestivum L.) bZIP transcription factor gene, TabZIP6, decreased the freezing tolerance of transgenic Arabidopsis seedlings by down-regulating the expression of CBFs. Plant Physiol. Biochem. 2018, 124, 100-111. [CrossRef] [PubMed]

71. Zhang, L.; Zhang, L.; Xia, C.; Zhao, G.; Liu, J.; Jia, J.; Kong, X. A novel wheat bZIP transcription factor, TabZIP60, confers multiple abiotic stress tolerances in transgenic Arabidopsis. Physiol. Plant 2015, 153, 538-554. [CrossRef] [PubMed] 
72. Wang, C.; Lu, G.; Hao, Y.; Guo, H.; Guo, Y.; Zhao, J.; Cheng, H. ABP9, a maize bZIP transcription factor, enhances tolerance to salt and drought in transgenic cotton. Planta 2017, 246, 453-469. [CrossRef] [PubMed]

73. Pan, Y.; Hu, X.; Li, C.; Xu, X.; Su, C.; Li, J.; Song, H.; Zhang, X.; Pan, Y. SlbZIP38, a tomato bZIP family gene down regulated by abscisic acid, is a negative regulator of drought and salt stress tolerance. Genes 2017, 8, 402. [CrossRef] [PubMed]

74. Babitha, K.C.; Ramu, S.V.; Nataraja, K.N.; Sheshshayee, M.S.; Udayakumar, M. EcbZIP60, a basic leucine zipper transcription factor from Eleusine coracana L. Improves abiotic stress tolerance in tobacco by activating unfolded protein response pathway. Mol. Breed. 2015, 35, 181. [CrossRef]

75. Xu, Z.; Ali, Z.; Xu, L.; He, X.; Huang, Y.; Yi, J.; Shao, H.; Ma, H.; Zhang, D. The nuclear protein GmbZIP110 has transcription activation activity and plays important roles in the response to salinity stress in soybean. Sci. Rep. 2016, 6, 20366. [CrossRef] [PubMed]

76. Li, Y.; Chen, Q.; Nan, H.; Li, X.; Lu, S.; Zhao, X.; Liu, B.; Guo, C.; Kong, F.; Cao, D. Overexpression of GmFDL19 enhances tolerance to drought and salt stresses in soybean. PLoS ONE 2017, 12, e0179554. [CrossRef] [PubMed]

77. Moon, S.J.; Han, S.Y.; Kim, D.Y.; Yoon, I.S.; Shin, D.; Byun, M.O.; Kwon, H.B.; Kim, B.G. Ectopic expression of a hot pepper bZIP-like transcription factor in potato enhances drought tolerance without decreasing tuber yield. Plant Mol. Biol. 2015, 89, 421-431. [CrossRef] [PubMed]

78. Liang, C.; Meng, Z.; Meng, Z.; Malik, W.; Yan, R.; Lwin, K.M.; Lin, F.; Wang, Y.; Sun, G.; Zhou, T.; et al. GhABF2, a bZIP transcription factor, confers drought and salinity tolerance in cotton (Gossypium hirsutum L.). Sci. Rep. 2016, 6, 35040. [CrossRef] [PubMed]

79. Huang, C.; Zhou, J.; Jie, Y.; Xing, H.; Zhong, Y.; Yu, W.; She, W.; Ma, Y.; Liu, Z.; Zhang, Y. A ramie bZIP transcription factor BnbZIP2 is involved in drought, salt, and heavy metal stress response. DNA Cell Biol. 2016, 35, 776-786. [CrossRef] [PubMed]

80. Jin, C.; Li, K.Q.; Xu, X.Y.; Zhang, H.P.; Chen, H.X.; Chen, Y.H.; Hao, J.; Wang, Y.; Huang, X.S.; Zhang, S.L. A novel NAC transcription factor, PbeNAC1, of Pyrus betulifolia confers cold and drought tolerance via interacting with PbeDREBs and activating the expression of stress-responsive genes. Front. Plant Sci. 2017, 8, 1049. [CrossRef] [PubMed]

81. Ebrahimian-Motlagh, S.; Ribone, P.A.; Thirumalaikumar, V.P.; Allu, A.D.; Chan, R.L.; Mueller-Roeber, B.; Balazadeh, S. JUNGBRUNNEN1 confers drought tolerance downstream of the HD-Zip I transcription factor AtHB13. Front. Plant Sci. 2017, 8, 2118. [CrossRef] [PubMed]

82. He, L.; Shi, X.; Wang, Y.; Guo, Y.; Yang, K.; Wang, Y. Arabidopsis ANAC069 binds to C[A/G]CG[T/G] sequences to negatively regulate salt and osmotic stress tolerance. Plant Mol. Biol. 2016, 93, 369-387. [CrossRef] [PubMed]

83. Cao, L.; Yu, Y.; Ding, X.; Zhu, D.; Yang, F.; Liu, B.; Sun, X.; Duan, X.; Yin, K.; Zhu, Y. The Glycine soja NAC transcription factor GsNAC019 mediates the regulation of plant alkaline tolerance and ABA sensitivity. Plant Mol. Biol. 2017, 95, 253-268. [CrossRef] [PubMed]

84. Hong, Y.; Zhang, H.; Huang, L.; Li, D.; Song, F. Overexpression of a stress-responsive NAC transcription factor gene ONAC022 improves drought and salt tolerance in rice. Front. Plant Sci. 2016, 7, 4. [CrossRef] [PubMed]

85. Chen, D.; Chai, S.; McIntyre, C.L.; Xue, G.-P. Overexpression of a predominantly root-expressed NAC transcription factor in wheat roots enhances root length, biomass and drought tolerance. Plant Cell Rep. 2018, 37, 225-237. [CrossRef] [PubMed]

86. Zhang, L.; Zhang, L.; Xia, C.; Zhao, G.; Jia, J.; Kong, X. The novel wheat transcription factor TaNAC47 enhances multiple abiotic stress tolerances in transgenic plants. Front. Plant Sci. 2016, 6, 1174. [CrossRef] [PubMed]

87. Duan, M.; Zhang, R.; Zhu, F.; Zhang, Z.; Gou, L.; Wen, J.; Dong, J.; Wang, T. A lipid-anchored NAC transcription factor is translocated into the nucleus and activates Glyoxalase I expression during drought stress. Plant Cell 2017, 29, 1748-1772. [CrossRef] [PubMed]

88. Zhu, M.; Chen, G.; Zhang, J.; Zhang, Y.; Xie, Q.; Zhao, Z.; Pan, Y.; Hu, Z. The abiotic stress-responsive NAC-type transcription factor SINAC4 regulates salt and drought tolerance and stress-related genes in tomato (Solanum lycopersicum). Plant Cell Rep. 2014, 33, 1851-1863. [CrossRef] [PubMed] 
89. Wang, G.; Zhang, S.; Ma, X.; Wang, Y.; Kong, F.; Meng, Q. A stress-associated NAC transcription factor (SINAC35) from tomato plays a positive role in biotic and abiotic stresses. Physiol. Plant. 2016, 158, 45-64. [CrossRef] [PubMed]

90. Mao, H.; Yu, L.; Han, R.; Li, Z.; Liu, H. ZmNAC55, a maize stress-responsive NAC transcription factor, confers drought resistance in transgenic Arabidopsis. Plant Physiol. Biochem. 2016, 105, 55-66. [CrossRef] [PubMed]

91. Guo, W.; Zhang, J.; Zhang, N.; Xin, M.; Peng, H.; Hu, Z.; Ni, Z.; Du, J. The wheat NAC transcription factor TaNAC2L is regulated at the transcriptional and post-translational levels and promotes heat stress tolerance in transgenic Arabidopsis. PLoS ONE 2015, 10, e0135667. [CrossRef] [PubMed]

92. Li, X.D.; Zhuang, K.Y.; Liu, Z.M.; Yang, D.Y.; Ma, N.N.; Meng, Q.W. Overexpression of a novel NAC-type tomato transcription factor, SINAM1, enhances the chilling stress tolerance of transgenic tobacco. J. Plant Physiol. 2016, 204, 54-65. [CrossRef] [PubMed]

93. Fang, L.; Su, L.; Sun, X.; Li, X.; Sun, M.; Karungo, S.K.; Fang, S.; Chu, J.; Li, S.; Xin, H. Expression of Vitis amurensis NAC26 in Arabidopsis enhances drought tolerance by modulating jasmonic acid synthesis. J. Exp. Bot. 2016, 67, 2829-2845. [CrossRef] [PubMed]

94. Dubos, C.; Stracke, R.; Grotewold, E.; Weisshaar, B.; Martin, C.; Lepiniec, L. MYB transcription factors in Arabidopsis. Trends Plant Sci. 2010, 15, 573-581. [CrossRef] [PubMed]

95. Li, X.; Xue, C.; Li, J.; Qiao, X.; Li, L.; Yu, L.; Huang, Y.; Wu, J. Genome-wide identification, evolution and functional divergence of MYB transcription factors in Chinese white pear (Pyrus bretschneideri). Plant Cell Physiol. 2016, 57, 824-847. [CrossRef] [PubMed]

96. Kim, J.H.; Hyun, W.Y.; Nguyen, H.N.; Jeong, C.Y.; Xiong, L.; Hong, S.W.; Lee, H. AtMyb7, a subgroup 4 R2R3 MYB, negatively regulates ABA-induced inhibition of seed germination by blocking the expression of the bZIP transcription factor ABI5. Plant Cell Environ. 2015, 38, 559-571. [CrossRef] [PubMed]

97. Liao, Y.; Zou, H.F.; Wang, H.W.; Zhang, W.K.; Ma, B.; Zhang, J.S.; Chen, S.Y. Soybean GmMYB76, GmMYB92, and GmMYB177 genes confer stress tolerance in transgenic Arabidopsis plants. Cell Res. 2008, 18, 1047-1060. [CrossRef] [PubMed]

98. Qin, Y.; Wang, M.; Tian, Y.; He, W.; Han, L.; Xia, G. Over-expression of TaMYB33 encoding a novel wheat MYB transcription factor increases salt and drought tolerance in Arabidopsis. Mol. Biol. Rep. 2012, 39, 7183-7192. [CrossRef] [PubMed]

99. Lee, S.B.; Kim, H.; Kim, R.J.; Suh, M.C. Overexpression of Arabidopsis MYB96 confers drought resistance in Camelina sativa via cuticular wax accumulation. Plant Cell Rep. 2014, 33, 1535-1546. [CrossRef] [PubMed]

100. Xu, R.; Wang, Y.; Zheng, H.; Lu, W.; Wu, C.; Huang, J.; Yan, K.; Yang, G.; Zheng, C. Salt-induced transcription factor MYB74 is regulated by the RNA-directed DNA methylation pathway in Arabidopsis. J. Exp. Bot. 2015, 66, 5997-6008. [CrossRef] [PubMed]

101. Chen, Y.; Chen, Z.; Kang, J.; Kang, D.; Gu, H.; Qin, G. AtMYB14 regulates cold tolerance in Arabidopsis. Plant Mol. Biol. Report. 2013, 31, 87-97. [CrossRef] [PubMed]

102. Wang, T.; Tohge, T.; Ivakov, A.; Mueller-Roeber, B.; Fernie, A.R.; Mutwil, M.; Schippers, J.H.; Persson, S. Salt-related MYB1 coordinates abscisic acid biosynthesis and signaling during salt stress in Arabidopsis. Plant Physiol. 2015, 169, 1027-1041. [CrossRef] [PubMed]

103. Yin, X.; Cui, Y.; Wang, M.; Xia, X. Overexpression of a novel MYB-related transcription factor, OsMYBR1, confers improved drought tolerance and decreased ABA sensitivity in rice. Biochem. Biophys. Res. Commun. 2017, 490, 1355-1361. [CrossRef] [PubMed]

104. Huang, P.; Chen, H.; Mu, R.; Yuan, X.; Zhang, H.S.; Huang, J. OsMYB511 encodes a MYB domain transcription activator early regulated by abiotic stress in rice. Genet. Mol. Res. 2015, 14, 9506-9517. [CrossRef] [PubMed]

105. Xiong, H.; Li, J.; Liu, P.; Duan, J.; Zhao, Y.; Guo, X.; Li, Y.; Zhang, H.; Ali, J.; Li, Z. Overexpression of OsMYB48-1, a novel MYB-related transcription factor, enhances drought and tolerance in rice. PLoS ONE 2014, 9, 1-13. [CrossRef] [PubMed]

106. Bi, H.; Luang, S.; Li, Y.; Bazanova, N.; Morran, S.; Song, Z.; Perera, M.A.; Hrmova, M.; Borisjuk, N.; Lopato, S. Identification and characterization of wheat drought-responsive MYB transcription factors involved in the regulation of cuticle biosynthesis. J. Exp. Bot. 2016, 67, 5363-5380. [CrossRef] [PubMed]

107. Li, M.J.; Qiao, Y.; Li, Y.Q.; Shi, Z.L.; Zhang, N.; Bi, C.L.; Guo, J.-K. A R2R3-MYB transcription factor gene in common wheat (namely TaMYBsm1) involved in enhancement of drought tolerance in transgenic Arabidopsis. J. Plant. Res. 2016, 129, 1097-1107. [CrossRef] [PubMed] 
108. Zhang, Z.; Hu, X.; Zhang, Y.; Miao, Z.; Xie, C.; Meng, X.Z.; Deng, J.; Wen, J.; Mysore, K.S.; Frugier, F.; et al. Opposing control by transcription factors MYB61 and MYB3 increases freezing tolerance by relieving c-repeat binding factor suppression. Plant Physiol. 2016, 172, 1306-1323. [PubMed]

109. Kiferle, C.; Fantini, E.; Bassolino, L.; Povero, G.; Spelt, C.; Buti, S.; Giuliano, G.; Quattrocchio, F.; Koes, R.; Perata, P.; et al. Tomato R2R3-MYB proteins SlANT1 and SlAN2: Same protein activity, different roles. PLoS ONE 2015, 10, e0136365. [CrossRef] [PubMed]

110. Cao, Z.H.; Zhang, S.Z.; Wang, R.K.; Zhang, R.F.; Hao, Y.J. Genome wide analysis of the apple MYB transcription factor family allows the identification of MdoMYB121 gene conferring abiotic stress tolerance in plants. PLoS ONE 2013, 8, e69955. [CrossRef]

111. Fang, Q.; Jiang, T.; Xu, L.; Liu, H.; Mao, H.; Wang, X.; Jiao, B.; Duan, Y.; Wang, Q.; Dong, Q.; et al. A salt-stress-regulator from the poplar R2R3 MYB family integrates the regulation of lateral root emergence and ABA signaling to mediate salt stress tolerance in Arabidopsis. Plant Physiol. Biochem. 2017, 114, 100-110. [CrossRef] [PubMed]

112. Wei, H.; Zhao, H.; Su, T.; Bausewein, A.; Greiner, S.; Harms, K.; Rausch, T. Chicory R2R3-MYB transcription factors CiMYB5 and CiMYB3 regulate fructan 1-exohydrolase expression in response to abiotic stress and hormonal cues. J. Exp. Bot. 2017, 68, 4323-4338. [CrossRef] [PubMed]

113. Sun, P.; Zhu, X.; Huang, X.; Liu, J.H. Overexpression of a stress-responsive MYB transcription factor of Poncirus trifoliata confers enhanced dehydration tolerance and increases polyamine biosynthesis. Plant Physiol. Biochem. 2014, 78, 71-79. [CrossRef] [PubMed]

114. Yao, L.; Jiang, Y.; Lu, X.; Wang, B.; Zhou, P.; Wu, T. A R2R3-MYB transcription factor from Lablab purpureus induced by drought increases tolerance to abiotic stress in Arabidopsis. Mol. Biol. Rep. 2016, 43, 1089-1100. [CrossRef] [PubMed]

115. He, M.; Wang, H.; Liu, Y.Z.; Gao, W.J.; Gao, Y.H.; Wang, F.; Zhou, Y.W. Cloning and characterization of ChiMYB in Chrysanthemum indicum with an emphasis on salinity stress tolerance. Genet. Mol. Res. 2016, 15, 1-17. [CrossRef] [PubMed]

116. Peng, X.; Liu, H.; Wang, D.; Shen, S. Genome-wide identification of the Jatropha curcas MYB family and functional analysis of the abiotic stress responsive gene JcMYB2. BMC Genom. 2016, 17, 1-12. [CrossRef] [PubMed]

117. Dou, T.-X.; Hu, C.-H.; Sun, X.-X.; Shao, X.-H.; Wu, J.-H.; Ding, L.-J.; Gao, J.; He, W.-D.; Biswas, M.-K.; Yang, Q.-S.; et al. MpMYBS3 as a crucial transcription factor of cold signaling confers the cold tolerance of banana. Plant Cell Tissue Organ 2015, 125, 93-106. [CrossRef]

118. Meng, X.; Wang, J.R.; Wang, G.D.; Liang, X.Q.; Li, X.D.; Meng, Q.W. An R2R3-MYB gene, LeAN2, positively regulated the thermo-tolerance in transgenic tomato. J. Plant Physiol. 2015, 175, 1-8. [CrossRef] [PubMed]

119. Murre, C.; McCaw, P.S.; Baltimore, D. A new DNA binding and dimerization motif in immunoglobulin enhancer binding, daughterless, MyoD, and myc proteins. Cell 1989, 56, 777-783. [CrossRef]

120. Feller, A.; Machemer, K.; Braun, E.L.; Grotewold, E. Evolutionary and comparative analysis of MYB and bHLH plant transcription factors. Plant J. 2011, 66, 94-116. [CrossRef] [PubMed]

121. Babitha, K.C.; Ramu, S.V.; Pruthvi, V.; Mahesh, P.; Nataraja, K.N.; Udayakumar, M. Co-expression of AtbHLH17 and AtWRKY28 confers resistance to abiotic stress in Arabidopsis. Transgenic Res. 2013, 22, 327-341. [CrossRef] [PubMed]

122. Ludwing, S.R.; Habera, F.L.; Dellaporta, S.L.; Wessler, S.R. Lc, a member of the maize R gene family responsible form tissue-specific anthocyanin production, encodes a protein similar to transcriptional activators and contains the myc-homology region. Proc. Natl. Acad. Sci. USA 1989, 86, 7092-7096. [CrossRef]

123. Babitha, K.C.; Vemanna, R.S.; Nataraja, K.N.; Udayakumar, M. Overexpression of EcbHLH57 transcription factor from Eleusine coracana L. In tobacco confers tolerance to salt, oxidative and drought stress. PLoS ONE 2015, 10, e0137098. [CrossRef] [PubMed]

124. Ohno, S.; Hosokawa, M.; Hoshino, A.; Kitamura, Y.; Morita, Y.; Park, K.I.; Nakashima, A.; Deguchi, A.; Tatsuzawa, F.; Doi, M.; et al. A bHLH transcription factor, DvIVS, is involved in regulation of anthocyanin synthesis in dahlia (Dahlia variabilis). J. Exp. Bot. 2011, 62, 5105-5116. [CrossRef] [PubMed]

125. Ito, S.; Song, Y.H.; Josephson-Day, A.R.; Miller, R.J.; Breton, G.; Olmstead, R.G. Flowering bHLH transcriptional activators control expression of the photoperiodic flowering regulator CONSTANS in Arabidopsis. Proc. Natl. Acad. Sci. USA 2012, 109, 3582-3587. [CrossRef] [PubMed] 
126. Wang, F.; Zhu, H.; Kong, W.; Peng, R.; Liu, Q.; Yao, Q. The Antirrhinum AmDEL gene enhances flavonoids accumulation and salt and drought tolerance in transgenic Arabidopsis. Planta 2016, 244, 59-73. [CrossRef] [PubMed]

127. Huang, X.S.; Wang, W.; Zhang, Q.; Liu, J.H. A basic helix-loop-helix transcription factor, PtrbHLH, of Poncirus trifoliata confers cold tolerance and modulates peroxidase-mediated scavenging of hydrogen peroxide. Plant Physiol. 2013, 162, 1178-1194. [CrossRef] [PubMed]

128. Peng, H.H.; Shan, W.; Kuang, J.F.; Lu, W.J.; Chen, J.Y. Molecular characterization of cold-responsive basic helix-loop-helix transcription factors MabHLHs that interact with MaICE1 in banana fruit. Planta 2013, 238, 937-953. [CrossRef] [PubMed]

129. Li, X.; Zhang, H.; Ai, Q.; Liang, G.; Yu, D. Two bHLH transcription factors, bHLH34 and bHLH104, regulate iron homeostasis in Arabidopsis thaliana. Plant Physiol. 2016, 170, 2478-2493. [CrossRef] [PubMed]

130. Wang, N.; Cui, Y.; Liu, Y.; Fan, H.; Du, J.; Huang, Z.; Yuan, Y.; Wu, H.; Ling, H.Q. Requirement and functional redundancy of $\mathrm{Ib}$ subgroup bHLH proteins for iron deficiency responses and uptake in Arabidopsis thaliana. Mol. Plant 2013, 6, 503-513. [CrossRef] [PubMed]

131. Maurer, F.; Naranjo Arcos, M.A.; Bauer, P. Responses of a triple mutant defective in three iron deficiency-induced basic helix-loop-helix genes of the subgroup $\mathrm{Ib}(2)$ to iron deficiency and salicylic acid. PLoS ONE 2014, 9, e99234. [CrossRef] [PubMed]

132. Zhao, M.; Song, A.; Li, P.; Chen, S.; Jiang, J.; Chen, F. A bHLH transcription factor regulates iron intake under Fe deficiency in chrysanthemum. Sci. Rep. 2014, 4, 6694. [CrossRef] [PubMed]

133. Rushton, P.J.; Somssich, I.E.; Ringler, P.; Shen, Q.J. WRKY transcription factors. Trends Plant Sci. 2010, 15, 247-258. [CrossRef] [PubMed]

134. Chen, L.; Song, Y.; Li, S.; Zhang, L.; Zou, C.; Yu, D. The role of WRKY transcription factors in plant abiotic stresses. Biochim. Biophys. Acta 2012, 1819, 120-128. [CrossRef] [PubMed]

135. Eulgem, T.; Rushton, P.J.; Robatzek, S.; Somssich, I.E. The WRKY superfamily of plant transcription factors. Trends Plant Sci. 2000, 5, 199-206. [CrossRef]

136. Yokotani, N.; Sato, Y.; Tanabe, S.; Chujo, T.; Shimizu, T.; Okada, K.; Yamane, H.; Shimono, M.; Sugano, S.; Takatsuji, H.; et al. WRKY76 is a rice transcriptional repressor playing opposite roles in blast disease resistance and cold stress tolerance. J. Exp. Bot. 2013, 64, 5085-5097. [CrossRef] [PubMed]

137. Qin, Y.; Tian, Y.; Liu, X. A wheat salinity-induced WRKY transcription factor TaWRKY93 confers multiple abiotic stress tolerance in Arabidopsis thaliana. Biochem. Biophys. Res. Commun. 2015, 464, 428-433. [CrossRef] [PubMed]

138. Chen, J.; Nolan, T.M.; Ye, H.; Zhang, M.; Tong, H.; Xin, P.; Chu, J.; Chu, C.; Li, Z.; Yin, Y. Arabidopsis WRKY46, WRKY54, and WRKY70 transcription factors are involved in brassinosteroid-regulated plant growth and drought responses. Plant Cell 2017, 29, 1425-1439. [CrossRef] [PubMed]

139. Shen, H.; Liu, C.; Zhang, Y.; Meng, X.; Zhou, X.; Chu, C.; Wang, X. OsWRKY30 is activated by MAP kinases to confer drought tolerance in rice. Plant Mol. Biol. 2012, 80, 241-253. [CrossRef] [PubMed]

140. Wang, C.; Deng, P.; Chen, L.; Wang, X.; Ma, H.; Hu, W.; Yao, N.; Feng, Y.; Chai, R.; Yang, G.; et al. A wheat WRKY transcription factor TaWRKY10 confers tolerance to multiple abiotic stresses in transgenic tobacco. PLoS ONE 2013, 8, e65120. [CrossRef] [PubMed]

141. Liu, B.; Hong, Y.B.; Zhang, Y.F.; Li, X.H.; Huang, L.; Zhang, H.J.; Li, D.Y.; Song, F.M. Tomato WRKY transcriptional factor SIDRW1 is required for disease resistance against Botrytis cinerea and tolerance to oxidative stress. Plant Sci. 2014, 227, 145-156. [CrossRef] [PubMed]

142. Sun, X.-C.; Gao, Y.-F.; Li, H.-R.; Yang, S.-Z.; Liu, Y.-S. Over-expression of SlWRKY39 leads to enhanced resistance to multiple stress factors in tomato. J. Plant Biol. 2015, 58, 52-60. [CrossRef]

143. Jia, H.; Wang, C.; Wang, F.; Liu, S.; Li, G.; Guo, X. GhWRKY68 reduces resistance to salt and drought in transgenic Nicotiana benthamiana. PLoS ONE 2015, 10, e120646. [CrossRef] [PubMed]

144. Ye, Y.J.; Xiao, Y.Y.; Han, Y.C.; Shan, W.; Fan, Z.Q.; Xu, Q.G.; Kuang, J.F.; Lu, W.J.; Lakshmanan, P.; Chen, J.Y. Banana fruit VQ motif-containing protein5 represses cold-responsive transcription factor MaWRKY26 involved in the regulation of JA biosynthetic genes. Sci. Rep. 2016, 6, 23632. [CrossRef] [PubMed]

145. Liang, Q.Y.; Wu, Y.H.; Wang, K.; Bai, Z.Y.; Liu, Q.L.; Pan, Y.Z.; Zhang, L.; Jiang, B.B. Chrysanthemum WRKY gene $D g W R K Y 5$ enhances tolerance to salt stress in transgenic chrysanthemum. Sci. Rep. 2017, 7, 4799. [CrossRef] [PubMed] 
146. Zhang, C.; Li, C.; Liu, J.; Lv, Y.; Yu, C.; Li, H.; Zhao, T.; Liu, B. The OsABF1 transcription factor improves drought tolerance by activating the transcription of COR413-TM1 in rice. J. Exp. Bot. 2017, 68, 4695-4707. [CrossRef] [PubMed]

147. Liu, J.; Chen, N.; Chen, F.; Cia, B.; Santo, S.D.; Tornielli, G.B.; Pezzotti, M.; Cheng, Z.-M.M. Genome-wide analysis and expression profile of the bZIP transcription factor gene family in grapevine (Vitis vinifera). BMC Genom. 2015, 15, 1-18. [CrossRef] [PubMed]

148. Jakoby, M. bZIP transcription factors in Arabidopsis. Trends Plant Sci. 2002, 7, 106-111. [CrossRef]

149. Weiste, C.; Pedrotti, L.; Selvanayagam, J.; Muralidhara, P.; FroĚschel, C.; Novak, O.; Ljung, K.; Hanson, J.; DroÈge-Laser, W. The Arabidopsis bZIP11 transcription factor links low-energy signalling to auxin-mediated control of primary root growth. PLoS Genet. 2017, 13, e1006607. [CrossRef] [PubMed]

150. Banerjee, A.; Roychoudhury, A. Abscisic-acid-dependent basic leucine zipper (bZIP) transcription factors in plant abiotic stress. Protoplasma 2015, 254,3-16. [CrossRef] [PubMed]

151. Sharma, P.D.; Singh, N.; Ahuja, P.S.; Reddy, T.V. Abscisic acid response element binding factor 1 is required for establishment of Arabidopsis seedlings during winter. Mol. Biol. Rep. 2011, 38, 5147-5159. [CrossRef] [PubMed]

152. Kim, S.; Kang, J.Y.; Cho, D.I.; Park, J.H.; Kim, S.Y. ABF2, an ABRE-binding bZIP factor, is an essential component of glucose signaling and its overexpression affects multiple stress tolerance. Plant J. 2004, 40, 75-87. [CrossRef] [PubMed]

153. Oh, S.J.; Song, S.I.; Kim, Y.S.; Jang, H.J.; Kim, S.Y.; Kim, M.; Kim, Y.K.; Nahm, B.H.; Kim, J.K. Arabidopsis $C B F 3 / D R E B 1 A$ and $A B F 3$ in transgenic rice increased tolerance to abiotic stress without stunting growth. Plant Physiol. 2005, 138, 341-351. [CrossRef] [PubMed]

154. Uno, Y.; Furihata, T.; Abe, H.; Yoshida, R.; Shinozaki, K.; Yamaguchi-Shinozaki, K. Arabidopsis basic leucine zipper transcription factors involved in an abscisic acid-dependent signal transduction pathway under drought and high-salinity conditions. Proc. Natl. Acad. Sci. USA 2000, 97, 11632-11637. [CrossRef] [PubMed]

155. Kong, Y.; Chen, S.; Yang, Y.; An, C. ABA-insensitive (ABI) 4 and ABI5 synergistically regulate DGAT1 expression in Arabidopsis seedlings under stress. FEBS Lett. 2013, 587, 3076-3082. [CrossRef] [PubMed]

156. Sun, X.; Li, Y.; Cai, H.; Bai, X.; Ji, W.; Ding, X.; Zhu, Y. The Arabidopsis AtbZIP1 transcription factor is a positive regulator of plant tolerance to salt, osmotic and drought stresses. J. Plant Res. 2012, 125, 429-438. [CrossRef] [PubMed]

157. Hartmann, L.; Pedrotti, L.; Weiste, C.; Fekete, A.; Schierstaedt, J.; Gottler, J.; Kempa, S.; Krischke, M.; Dietrich, K.; Mueller, M.J.; et al. Crosstalk between two bZIP signaling pathways orchestrates salt-induced metabolic reprogramming in Arabidopsis roots. Plant Cell 2015, 27, 2244-2260. [CrossRef] [PubMed]

158. Liu, C.; Mao, B.; Ou, S.; Wang, W.; Liu, L.; Wu, Y.; Chu, C.; Wang, X. OsbZIP71, a bZIP transcription factor, confers salinity and drought tolerance in rice. Plant Mol. Biol. 2014, 84, 19-36. [CrossRef] [PubMed]

159. Zong, W.; Tang, N.; Yang, J.; Peng, L.; Ma, S.; Xu, Y.; Li, G.; Xiong, L. Feedback regulation of ABA signaling and biosynthesis by a bZIP transcription factor targets drought-resistance-related genes. Plant Physiol. 2016, 171, 2810-2825. [CrossRef] [PubMed]

160. Dey, A.; Samanta, M.K.; Gayen, S.; Sen, S.K.; Maiti, M.K. Enhanced gene expression rather than natural polymorphism in coding sequence of the OsbZIP23 determines drought tolerance and yield improvement in rice genotypes. PLoS ONE 2016, 11, e0150763. [CrossRef] [PubMed]

161. Tak, H.; Mhatre, M. Cloning and molecular characterization of a putative bZIP transcription factor VvbZIP23 from Vitis vinifera. Protoplasma 2013, 250, 333-345. [CrossRef] [PubMed]

162. Cheng, L.; Xu, X.; Chen, X.; Li, S.; Yin, J.; Li, L.; Hussain, J.; Zhang, Y. Isolation and functional characterization of a salt responsive transcriptional factor, LrbZIP from lotus root (Nelumbo nucifera Gaertn). Mol. Biol. Rep. 2013, 40, 4033-4045. [CrossRef] [PubMed]

163. Ji, X.; Liu, G.; Liu, Y.; Zheng, L.; Nie, X.; Wang, Y. The bZIP protein from Tamarix hispida, ThbZIP1, is ACGT elements binding factor that enhances abiotic stress signaling in Transgenic Arabidopsis. BMC Plant Biol. 2013, 13, 1-13. [CrossRef] [PubMed]

164. Souer, E.; van Houwelingen, A.; Kloos, D.; Mol, J.; Koes, R. The no apical meristem gene of petunia is required for pattern formation in embryos and flowers and is expressed at meristem and primordia boundaries. Cell 1996, 85, 159-170. [CrossRef]

165. Aida, M.; Ishida, T.; Fukaki, H.; Fujisawa, H.; Tasaka, M. Genes involved in organ separation in Arabidopsis: An analysis of the cup-shaped cotyledon mutant. Plant Cell 1997, 9, 841-857. [CrossRef] [PubMed] 
166. Lv, Z.; Wang, S.; Zhang, F.; Chen, L.; Hao, X.; Pan, Q.; Fu, X.; Li, L.; Sun, X.; Tang, K. Overexpression of a novel NAC domain-containing transcription factor gene (AaNAC1) enhances the content of artemisinin and increases tolerance to drought and Botrytis cinerea in Artemisia annua. Plant Cell Physiol. 2016, 57, 1961-1971. [CrossRef] [PubMed]

167. Puranik, S.; Sahu, P.P.; Srivastava, P.S.; Prasad, M. NAC proteins: Regulation and role in stress tolerance. Trends Plant Sci. 2012, 17, 369-381. [CrossRef] [PubMed]

168. Shahnejat-Bushehri, S.; Tarkowska, D.; Sakuraba, Y.; Balazadeh, S. Arabidopsis NAC transcription factor JUB1 regulates GA/BR metabolism and signalling. Nat. Plants 2016, 2, 16013. [CrossRef] [PubMed]

169. Liu, Y.; Sun, J.; Wu, Y. Arabidopsis ATAF1 enhances the tolerance to salt stress and ABA in transgenic rice. J. Plant Res. 2016, 129, 955-962. [CrossRef] [PubMed]

170. Seok, H.Y.; Woo, D.H.; Nguyen, L.V.; Tran, H.T.; Tarte, V.N.; Mehdi, S.M.; Lee, S.Y.; Moon, Y.H. Arabidopsis AtNAP functions as a negative regulator via repression of AREB1 in salt stress response. Planta 2017, 245, 329-341. [CrossRef] [PubMed]

171. Fang, Y.; Liao, K.; Du, H.; Xu, Y.; Song, H.; Li, X.; Xiong, L. A stress-responsive NAC transcription factor SNAC3 confers heat and drought tolerance through modulation of reactive oxygen species in rice. J. Exp. Bot. 2015, 66, 6803-6817. [CrossRef] [PubMed]

172. Chen, X.; Wang, Y.; Lv, B.; Li, J.; Luo, L.; Lu, S.; Zhang, X.; Ma, H.; Ming, F. The NAC family transcription factor OsNAP confers abiotic stress response through the ABA pathway. Plant Cell Physiol. 2014, 55, 604-619. [CrossRef] [PubMed]

173. Yu, X.; Liu, Y.; Wang, S.; Tao, Y.; Wang, Z.; Shu, Y.; Peng, H.; Mijiti, A.; Wang, Z.; Zhang, H.; et al. CarNAC4, a NAC -type chickpea transcription factor conferring enhanced drought and salt stress tolerances in Arabidopsis. Plant Cell Rep. 2016, 35, 613-627. [CrossRef] [PubMed]

174. Thirumalaikumar, V.P.; Devkar, V.; Mehterov, N.; Ali, S.; Ozgur, R.; Turkan, I.; Mueller-Roeber, B.; Balazadeh, S. NAC transcription factor JUNGBRUNNEN1 enhances drought tolerance in tomato. Plant Biotechnol. J. 2018, 16, 354-366. [CrossRef] [PubMed]

175. Zhao, X.; Yang, X.; Pei, S.; He, G.; Wang, X.; Tang, Q.; Jia, C.; Lu, Y.; Hu, R.; Zhou, G. The miscanthus NAC transcription factor MINAC9 enhances abiotic stress tolerance in transgenic Arabidopsis. Gene 2016, 586, 158-169. [CrossRef] [PubMed]

176. Lu, M.; Zhang, D.-F.; Shi, Y.-S.; Song, Y.-C.; Wang, T.-Y.; Li, Y. Expression of SbSNAC1, a NAC transcription factor from sorghum, confers drought tolerance to transgenic Arabidopsis. Plant Cell Tissue Organ 2013, 115, 443-455. [CrossRef]

177. Xu, Z.; Wang, C.; Xue, F.; Zhang, H.; Ji, W. Wheat NAC transcription factor TaNAC29 is involved in response to salt stress. Plant Physiol. Biochem. 2015, 96, 356-363. [CrossRef] [PubMed]

178. Huang, L.; Hong, Y.; Zhang, H.; Li, D.; Song, F. Rice NAC transcription factor ONAC095 plays opposite roles in drought and cold stress tolerance. BMC Plant Biol. 2016, 16, 203. [CrossRef] [PubMed]

179. An, J.P.; Li, R.; Qu, F.J.; You, C.X.; Wang, X.F.; Hao, Y.J. An apple NAC transcription factor negatively regulates cold tolerance via CBF-dependent pathway. J. Plant Physiol. 2018, 221, 74-80. [CrossRef] [PubMed]

180. Tak, H.; Negi, S.; Ganapathi, T.R. Banana NAC transcription factor MusaNAC042 is positively associated with drought and salinity tolerance. Protoplasma 2017, 254, 803-816. [CrossRef] [PubMed]

181. Wei, T.; Deng, K.; Liu, D.; Gao, Y.; Liu, Y.; Yang, M.; Zhang, L.; Zheng, X.; Wang, C.; Song, W.; et al. Ectopic Expression of DREB Transcription Factor, AtDREB1A, confers tolerance to drought in transgenic Salvia miltiorrhiza. Plant Cell Physiol. 2016, 57, 1593-1609. [CrossRef] [PubMed]

182. Ahn, H.; Jung, I.; Shin, S.J.; Park, J.; Rhee, S.; Kim, J.K.; Jung, W.; Kwon, H.B.; Kim, S. Transcriptional network analysis reveals drought resistance mechanisms of AP2/ERF transgenic rice. Front. Plant Sci. 2017, 8, 1044. [CrossRef] [PubMed]

183. Sewelam, N.; Kazan, K.; Thomas-Hall, S.R.; Kidd, B.N.; Manners, J.M.; Schenk, P.M. Ethylene response factor 6 is a regulator of reactive oxygen species signaling in Arabidopsis. PLoS ONE 2013, 8, e70289. [CrossRef] [PubMed]

184. Krishnaswamy, S.; Verma, S.; Rahman, M.H.; Kav, N.N. Functional characterization of four APETALA2-family genes (RAP2.6, RAP2.6L, DREB19 and DREB26) in Arabidopsis. Plant Mol. Biol. 2011, 75, 107-127. [CrossRef] [PubMed] 
185. Gupta, K.; Jha, B.; Agarwal, P.K. A dehydration-responsive element binding (DREB) transcription factor from the succulent halophyte Salicornia brachiata enhances abiotic stress tolerance in transgenic tobacco. Mar. Biotechnol. 2014, 16, 657-673. [CrossRef] [PubMed]

186. Zhang, X.; Liu, X.; Wu, L.; Yu, G.; Wang, X.; Ma, H. The SsDREB transcription factor from the succulent halophyte Suaeda salsa enhances abiotic stress tolerance in transgenic tobacco. Int. J. Genom. 2015, 2015, 875497. [CrossRef]

187. Pandey, N.; Ranjan, A.; Pant, P.; Tripathi, R.K.; Ateek, F.; Pandey, N.P.; Patre, U.V.; Sawant, S.V. CAMTA 1 regulates drought responses in Arabidopsis thaliana. BMC Genom. 2013, 14, 216. [CrossRef] [PubMed]

188. Prasad, K.V.; Abdel-Hameed, A.A.; Xing, D.; Reddy, A.S. Global gene expression analysis using RNA-seq uncovered a newm role for SR1/CAMTA3 transcription factor in salt stress. Sci. Rep. 2016, 6, 27021. [CrossRef] [PubMed]

189. Renau-Morata, B.; Molina, R.V.; Carrillo, L.; Cebolla-Cornejo, J.; Sánchez-Perales, M.; Pollmann, S.; Domínguez-Figueroa, J.; Corrales, A.R.; Flexas, J.; Vicente-Carbajosa, J.; et al. Ectopic expression of CDF3 genes in tomato enhances biomass production and yield under salinity stress conditions. Front. Plant Sci. 2017, 8, 660. [CrossRef] [PubMed]

190. Ding, W.; Wang, Y.; Fang, W.; Gao, S.; Li, X.; Xiao, K. TaZAT8, a C2H2-ZFP type transcription factor gene in wheat, plays critical roles in mediating tolerance to pi deprivation through regulating $\mathrm{p}$ acquisition, ROS homeostasis and root system establishment. Physiol. Plant 2016, 158, 297-311. [CrossRef] [PubMed]

191. You, J.; Chan, Z. ROS regulation during abiotic stress responses in crop plants. Front. Plant Sci. 2015, 6, 1092. [CrossRef] [PubMed]

192. Mabuchi, K.; Maki, H.; Itaya, T.; Suzuki, T.; Nomoto, M.; Sakaoka, S.; Morikami, A.; Higashiyama, T.; Tada, Y.; Busch, W.; Tsukagoshi, H. MYB30 links ROS signaling, root cell elongation, and plant immune responses. Proc. Natl. Acad. Sci. USA 2018. [CrossRef] [PubMed]

193. Wei, Q.; Luo, Q.; Wang, R.; Zhang, F.; He, Y.; Zhang, Y.; Qiu, D.; Li, K.; Chang, J.; Yang, G.; et al. A wheat R2R3-type MYB transcription factor TaODORANT1 positively regulates drought and salt stress responses in transgenic tobacco plants. Front. Plant Sci. 2017, 8, 1374. [CrossRef] [PubMed]

194. Zhao, Q.; Xiang, X.; Liu, D.; Yang, A.; Wang, Y. Tobacco transcription factor NtbHLH123 confers tolerance to cold stress by regulating the NtCBF pathway and reactive oxygen species homeostasis. Front. Plant Sci. 2018, 9, 381. [CrossRef] [PubMed]

195. Geng, J.; Liu, J. The transcription factor CsbHLH18 of sweet orange functions in modulation of cold tolerance and homeostasis of reactive oxygen species by regulating the antioxidant gene. J. Exp. Bot. 2018, 69, 2677-2692. [CrossRef] [PubMed]

196. Kiranmai, K.; Lokanadha Rao, G.; Pandurangaiah, M.; Nareshkumar, A.; Amaranatha Reddy, V.; Lokesh, U.; Venkatesh, B.; Anthony Johnson, A.M.; Sudhakar, C. A novel WRKY transcription factor, MuWRKY3 (Macrotyloma uniflorum lam. Verdc.) enhances drought stress tolerance in transgenic groundnut (Arachis hypogaea L.) plants. Front. Plant Sci. 2018, 9, 346. [CrossRef] [PubMed]

197. Hong, C.; Cheng, D.; Zhang, G.; Zhu, D.; Chen, Y.; Tan, M. The role of ZmWRKY4 in regulating maize antioxidant defense under cadmium stress. Biochem. Biophys. Res. Commun. 2017, 482, 1504-1510. [CrossRef] [PubMed]

198. Wang, J.; Zhang, L.; Cao, Y.; Qi, C.; Li, S.; Liu, L.; Wang, G.; Mao, A.; Ren, S.; Guo, Y.D. CsATAF1 positively regulates drought stress tolerance by an ABA-dependent pathway and by promoting ROS scavenging in cucumber. Plant Cell Physiol. 2018, 59, 930-945. [CrossRef] [PubMed]

199. Banerjee, A.; Roychoudhury, A. WRKY proteins: Signaling and regulation of expression during abiotic stress responses. Sci. World J. 2015, 2015, 807560. [CrossRef] [PubMed]

200. Cordeiro, A.M.; Figueiredo, D.D.; Tepperman, J.; Borba, A.R.; Lourenco, T.; Abreu, I.A.; Ouwerkerk, P.B.; Quail, P.H.; Margarida Oliveira, M.; Saibo, N.J. Rice phytochrome-interacting factor protein OsPIF14 represses OsDREB1B gene expression through an extended N-box and interacts preferentially with the active form of Phytochrome B. Biochim. Biophys. Acta 2016, 1859, 393-404. [CrossRef] [PubMed]

201. Safari-Alighiarloo, N.; Taghizadeh, M.; Rezaei-Tavirani, M.; Goliaei, B.; Peyvandi, A.A. Protein-protein interaction networks (PPI) and complex diseases. Gastroenterol. Hepatol. Bed Bench 2014, 7, 17-31. [PubMed]

202. Jaeger, S.; Aloy, P. From protein interaction networks to novel therapeutic strategies. IUBMB Life 2012, 64, 529-537. [CrossRef] [PubMed] 
203. Gahlaut, V.; Jaiswal, V.; Kumar, A.; Gupta, P.K. Transcription factors involved in drought tolerance and their possible role in developing drought tolerant cultivars with emphasis on wheat (Triticum aestivum L.). Theor. Appl. Genet. 2016, 129, 2019-2042. [CrossRef] [PubMed]

204. Pireyre, M.; Burow, M. Regulation of MYB and bHLH transcription factors: A glance at the protein level. Mol. Plant 2015, 8, 378-388. [CrossRef] [PubMed]

205. Weltmeier, F.; Ehlert, A.; Mayer, C.S.; Dietrich, K.; Wang, X.; Schutze, K.; Alonso, R.; Harter, K.; Vicente-Carbajosa, J.; Droge-Laser, W. Combinatorial control of Arabidopsis proline dehydrogenase transcription by specific heterodimerisation of bZIP transcription factors. EMBO J. 2006, 25, 3133-3143. [CrossRef] [PubMed]

206. Jaradat, M.R.; Feurtado, J.A.; Huang, D.; Lu, Y.; Cutler, A.J. Multiple roles of the transcription factor AtMYBR1/AtMYB44 in ABA signaling, stress responses, and leaf senescence. BMC Plant Biol. 2013, 13, 192. [CrossRef] [PubMed]

207. Deng, C.; Ye, H.; Fan, M.; Pu, T.; Yan, J. The rice transcription factors OsICE confer enhanced cold tolerance in transgenic Arabidopsis. Plant Signal. Behav. 2017, 12, e1316442. [CrossRef] [PubMed]

208. Feng, F.; Qi, W.; Lv, Y.; Yan, S.; Xu, L.; Yang, W.; Yuan, Y.; Chen, Y.; Zhao, H.; Song, R. Opaque11 is a central Hub of the regulatory network for maize endosperm development and nutrient metabolism. Plant Cell 2018, 30, 375-396. [CrossRef] [PubMed]

209. Wang, L.; Zheng, L.; Zhang, C.; Wang, Y.; Lu, M.; Gao, C. ThWRKY4 from Tamarix hispida can form homodimers and heterodimers and is involved in abiotic stress responses. Int. J. Mol. Sci. 2015, 16, 27097-27106. [CrossRef] [PubMed]

210. Yang, G.; Zhang, W.; Liu, Z.; Yi-Maer, A.Y.; Zhai, M.; Xu, Z. Both JrWRKY2 and JrWRKY7 of Juglans regia mediate responses to abiotic stresses and abscisic acid through formation of homodimers and interaction. Plant Biol. 2017, 19, 268-278. [CrossRef] [PubMed]

211. Li, S.; Fu, Q.; Chen, L.; Huang, W.; Yu, D. Arabidopsis thaliana WRKY25, WRKY26, and WRKY 33 coordinate induction of plant thermotolerance. Planta 2011, 233, 1237-1252. [CrossRef] [PubMed]

212. Chen, Y.F.; Li, L.Q.; Xu, Q.; Kong, Y.H.; Wang, H.; Wu, W.H. The WRKY6 transcription factor modulates phosphate1 expression in response to low pi stress in Arabidopsis. Plant Cell 2009, 21, 3554-3566. [CrossRef] [PubMed]

213. Harris, J.C.; Sornaraj, P.; Taylor, M.; Bazanova, N.; Baumann, U.; Lovell, B.; Langridge, P.; Lopato, S.; Hrmova, M. Molecular interactions of the $\gamma$-clade homeodomain-leucine zipper class i transcription factors during the wheat response to water deficit. Plant Mol. Biol. 2016, 90, 435-452. [CrossRef] [PubMed]

214. Liu, S.; Li, M.; Su, L.; Ge, K.; Li, L.; Li, X.; Liu, X.; Li, L. Negative feedback regulation of ABA biosynthesis in peanut (Arachis hypogaea): A transcription factor complex inhibits AhNCED1 expression during water stress. Sci. Rep. 2016, 6, 37943. [CrossRef] [PubMed]

215. Shan, W.; Kuang, J.F.; Lu, W.J.; Chen, J.Y. Banana fruit NAC transcription factor MaNAC1 is a direct target of MaICE1 and involved in cold stress through interacting with macbf1. Plant Cell Environ. 2014, 37, 2116-2127. [CrossRef] [PubMed]

216. Alves, M.S.; Dadalto, S.P.; Goncalves, A.B.; de Souza, G.B.; Barros, V.A.; Fietto, L.G. Transcription factor functional protein-protein interactions in plant defense responses. Proteomes 2014, 2, 85-106. [CrossRef] [PubMed]

217. Singh, K.; Foley, R.C.; Onate-Sanchez, L. Transcription factors in plant defense and stress responses. Curr. Opin. Plant Biol. 2002, 5, 430-436. [CrossRef]

218. Parveen, S.; Pandey, A.; Jameel, N.; Chakraborty, S.; Chakraborty, N. Transcriptional regulation of chickpea ferritin CaFer1 influences its role in iron homeostasis and stress response. J. Plant Physiol. 2018, 222, 9-16. [CrossRef] [PubMed]

219. Vivek, P.J.; Resmi, M.S.; Sreekumar, S.; Sivakumar, K.C.; Tuteja, N.; Soniya, E.V. Calcium-dependent protein kinase in ginger binds with Importin- $\alpha$ through its junction domain for nuclear localization, and further interacts with NAC transcription factor. Front. Plant Sci. 2016, 7, 1909. [CrossRef] [PubMed]

220. Bian, S.; Jin, D.; Li, R.; Xie, X.; Gao, G.; Sun, W.; Li, Y.; Zhai, L.; Li, X. Genome-wide analysis of CCA1-like proteins in soybean and functional characterization of GmMYB138a. Int. J. Mol. Sci. 2017, 18, 2040. [CrossRef] [PubMed] 
221. Li, D.; Li, Y.; Zhang, L.; Wang, X.; Zhao, Z.; Tao, Z.; Wang, J.; Wang, J.; Lin, M.; Li, X.; et al. Arabidopsis ABA receptor RCAR1/PYL9 interacts with an R2R3-Type MYB transcription factor, AtMYB44. Int. J. Mol. Sci. 2014, 15, 8473-8490. [CrossRef] [PubMed]

222. Zhou, L.J.; Li, Y.Y.; Zhang, R.F.; Zhang, C.L.; Xie, X.B.; Zhao, C.; Hao, Y.J. The small ubiquitin-like modifier E3 ligase MdSIZ1 promotes anthocyanin accumulation by sumoylating MdMYB1 under low-temperature conditions in apple. Plant Cell Environ. 2017, 40, 2068-2080. [CrossRef] [PubMed]

223. Wang, J.; Cheng, G.; Wang, C.; He, Z.; Lan, X.; Zhang, S.; Lan, H. The bHLH transcription factor CgbHLH001 is a potential interaction partner of CDPK in halophyte Chenopodium glaucum. Sci. Rep. 2017, 7, 8441. [CrossRef] [PubMed]

224. Hu, Y.; Chen, L.; Wang, H.; Zhang, L.; Wang, F.; Yu, D. Arabidopsis transcription factor WRKY8 functions antagonistically with its interacting partner vq9 to modulate salinity stress tolerance. Plant J. 2013, 74, 730-745. [CrossRef] [PubMed]

225. Tang, N.; Ma, S.; Zong, W.; Yang, N.; Lv, Y.; Yan, C.; Guo, Z.; Li, J.; Li, X.; Xiang, Y.; Song, H.; et al. MODD mediates deactivation and degradation of OsbZIP46 to negatively regulate ABA signaling and drought resistance in rice. Plant Cell 2016, 28, 2161-2177. [CrossRef] [PubMed]

226. Feng, Z.J.; Cui, X.Y.; Cui, X.Y.; Chen, M.; Yang, G.X.; Ma, Y.Z.; He, G.Y.; Xu, Z.S. The soybean GmDi19-5 interacts with GmLEA3.1 and increases sensitivity of transgenic plants to abiotic stresses. Front. Plant Sci. 2015, 6, 179. [CrossRef] [PubMed]

227. Tardif, G.; Kane, N.A.; Adam, H.; Labrie, L.; Major, G.; Gulick, P.; Sarhan, F.; Laliberte, J.F. Interaction network of proteins associated with abiotic stress response and development in wheat. Plant Mol. Biol. 2007, 63, 703-718. [CrossRef] [PubMed]

228. Zhu, S.; Li, W.; Liu, J.; Chen, C.H.; Liao, Q.; Xu, P.; Xu, H.; Xiao, T.; Cao, Z.; Peng, J.; et al. Genome-scale deletion screening of human long non-coding RNAs using a paired-guide RNA CRISPR-Cas9 library. Nat. Biotechnol. 2016, 34, 1279-1286. [CrossRef] [PubMed]

229. Markel, H.; Chandler, J.; Werr, W. Translational fusions with the engrailed repressor domain efficiently convert plant transcription factors into dominant-negative functions. Nucleic Acids Res. 2002, 30, 4709-4719. [CrossRef] [PubMed]

230. Rizhsky, L.; Liang, H.; Shuman, J.; Shulaev, V.; Davletova, S.; Mittler, R. When defense pathways collide. The response of Arabidopsis to a combination of drought and heat stress. Plant Physiol. 2004, 134, 1683-1696. [CrossRef] [PubMed]

231. Seo, P.J.; Xiang, F.; Qiao, M.; Park, J.Y.; Lee, Y.N.; Kim, S.G.; Lee, Y.H.; Park, W.J.; Park, C.M. The MYB96 transcription factor mediates abscisic acid signaling during drought stress response in Arabidopsis. Plant Physiol. 2009, 151, 275-289. [CrossRef] [PubMed]

232. Hooker, T.S.; Millar, A.A.; Kunst, L. Significance of the expression of the CER6 condensing enzyme for cuticular wax production in Arabidopsis. Plant Physiol. 2002, 129, 1568-1580. [CrossRef] [PubMed]

233. Kasuga, M.; Miura, S.; Shinozaki, K.; Yamaguchi-Shinozaki, K. A combination of the Arabidopsis DREB1A gene and stress-inducible $r d 29 \mathrm{~A}$ promoter improved drought- and low-temperature stress tolerance in tobacco by gene transfer. Plant Cell Physiol. 2004, 45, 346-350. [CrossRef] [PubMed]

234. Shabala, S. Learning from halophytes: Physiological basis and strategies to improve abiotic stress tolerance in crops. Ann. Bot. 2013, 112, 1209-1221. [CrossRef] [PubMed]

235. Flowers, T.J.; Colmer, T.D. Plant salt tolerance: Adaptations in halophytes. Ann. Bot. 2015, 115, 327-331. [CrossRef] [PubMed]

(C) 2018 by the authors. Licensee MDPI, Basel, Switzerland. This article is an open access article distributed under the terms and conditions of the Creative Commons Attribution (CC BY) license (http://creativecommons.org/licenses/by/4.0/). 